ARTICLE

DOI: $10.1038 / s 41467-017-02123-w$

\title{
Protein-inspired antibiotics active against vancomycin- and daptomycin-resistant bacteria
}

Mark A.T. Blaskovich (1) 1, Karl A. Hansford (1) 1, Yujing Gong1, Mark S. Butler (1) ', Craig Muldoon', Johnny X. Huang ${ }^{1}$, Soumya Ramu1, Alberto B. Silva1,5, Mu Cheng ${ }^{1}$, Angela M. Kavanagh', Zyta Ziora (1) 1, Rajaratnam Premraj ${ }^{1}$, Fredrik Lindahl'1, Tanya A. Bradford1', June C. Lee (1) 1, Tomislav Karoli (1) 1,6, Ruby Pelingon', David J. Edwards', Maite Amado1, Alysha G. Elliott (1) 1, Wanida Phetsang1', Noor Huda Daud', Johan E. Deecke', Hanna E. Sidjabat ${ }^{2}$, Sefetogi Ramaologa1, Johannes Zuegg (10 1, Jason R. Betley 3,7, Andrew P.G. Beevers ${ }^{3,8}$, Richard A.G. Smith ${ }^{3,9}$, Jason A. Roberts ${ }^{2,4}$, David L. Paterson ${ }^{2} \&$ Matthew A. Cooper ${ }^{1}$

The public health threat posed by a looming 'post-antibiotic' era necessitates new approaches to antibiotic discovery. Drug development has typically avoided exploitation of membrane-binding properties, in contrast to nature's control of biological pathways via modulation of membrane-associated proteins and membrane lipid composition. Here, we describe the rejuvenation of the glycopeptide antibiotic vancomycin via selective targeting of bacterial membranes. Peptide libraries based on positively charged electrostatic effector sequences are ligated to $\mathrm{N}$-terminal lipophilic membrane-insertive elements and then conjugated to vancomycin. These modified lipoglycopeptides, the 'vancapticins', possess enhanced membrane affinity and activity against methicillin-resistant Staphylococcus aureus (MRSA) and other Gram-positive bacteria, and retain activity against glycopeptide-resistant strains. Optimised antibiotics show in vivo efficacy in multiple models of bacterial infection. This membrane-targeting strategy has potential to 'revitalise' antibiotics that have lost effectiveness against recalcitrant bacteria, or enhance the activity of other intravenousadministered drugs that target membrane-associated receptors.

\footnotetext{
${ }^{1}$ Institute for Molecular Bioscience, The University of Queensland, St. Lucia, QLD 4072, Australia. ${ }^{2}$ UQ Centre for Clinical Research, The University of Queensland, Royal Brisbane and Women's Hospital Campus, Brisbane, QLD 4029, Australia. ${ }^{3}$ AdProTech Ltd, Chesterford Research Park, Saffron Walden, Essex CB10 1XL, UK. ${ }^{4}$ School of Pharmacy, The University of Queensland, Brisbane, QLD 4102, Australia. ${ }^{5}$ Present address: AC Immune SA, EPFL Innovation Park, CH-1015 Lausanne, Switzerland. ' Present address: Novasep (Dynamit Nobel Explosivstoff und Systemtechnik), Kalkstrasse 218, 51377 Leverkusen, Germany. ${ }^{7}$ Present address: Illumina Cambridge Ltd, Capital Park, Fulbourn, Cambridge, CB21 5XE, UK. ${ }^{8}$ Present address: Sterling Pharma Solutions, Sterling Place, Dudley, Cramlington, Northumberland NE23 7QG, UK. 'P Present address: School of Immunology and Microbial Science Kings College London, Guy's Hospital, London, SE1 9RT, UK. Correspondence and requests for materials should be addressed to M.A.T.B. (email: m.blaskovich@uq.edu.au) or to M.A.C. (email: m.cooper@uq.edu.au)
} 
A ntibiotic resistant bacteria pose a grave threat to human health and there now is an urgent need to develop new antibiotics $^{1-5}$. Methicillin-resistant Staphylococcus aureus (MRSA), a major cause of community and hospital-acquired infections, leads to significant morbidity and mortality $1,6,7$. Vancomycin is often used to treat MRSA infections, but clinical isolates that are resistant are increasingly common ${ }^{6}$ : VISA vancomycin-intermediate $S$. aureus: MIC (minimum inhibitory concentration) 4-8 $\mathrm{g} \mathrm{mL}^{-1}$; hVISA - heteroresistant VISA: predominantly susceptible but with a resistant subpopulation; and, more rarely ${ }^{7}$, VRSA - vancomycin-resistant S. aureus: $\mathrm{MIC} \geq 16 \mu \mathrm{g} \mathrm{mL}^{-1}$. Even moderate reductions in vancomycin susceptibility (MIC shift from $\leq 1$ to $1.5-2.0 \mu \mathrm{g} \mathrm{mL}^{-1}$ ) can lead to significantly worse clinical outcomes ${ }^{6,8}, 9$. In the last 15 years antimicrobial agents such as daptomycin and linezolid have emerged as approved therapeutic compounds for vancomycinresistant bacteria ${ }^{10}$, but resistance to both of these antibiotics was identified in vancomycin-resistant enterococci (VRE) and MRSA shortly after their approval ${ }^{11,12}$.

Drug development traditionally focuses on optimising target affinity, selectivity and protein binding in the context of drug pharmacodynamics ${ }^{13}$, but rarely assesses membrane-binding properties $^{14}$. In contrast, nature exploits subtle changes in the composition of biological membranes to control signal transduction, vesicular transport and receptor recycling with membrane-associated proteins such as $\mathrm{Ras}^{15}, \mathrm{Src}^{16}, \mathrm{Rab}^{17}, \mathrm{HIV}-1$ $\mathrm{GAG}^{18}$ and MARCKS ${ }^{19}$. In these proteins, $N$-terminal and/or C-terminal lipophilic groups (myristoyl, palmitoyl, geranyl, farnesyl) and clusters of basic amino acids act as an electrostatic 'switch' to control translocation between the cytosol and membrane surface via selective phosphorylation of serine and tyrosine residues ${ }^{16,20,21}$. We postulated that appending such motifs to drugs acting on membrane-associated targets could enhance membrane binding and concomitantly increase drug concentration at the target site ${ }^{20}$. The potential also exists to discriminate between different types of membranes to increase drug selectivity. Given the alarming rise of multi-drug resistant bacteria and paucity of new antibiotics in the pipeline, we validated this approach using the glycopeptide antibiotic vancomycin.

In this study, we designed and synthesised a series of vancomycin derivatives, designated vancapticins, by appending membrane targeting motifs onto the $C$-terminus of vancomycin. The vancapticins display Gram-positive activity, including activity against vancomycin-resistant strains. The vancapticins were highly efficacious in multiple infections models in mice, with a low propensity for innate and induced resistance, and a pharmacokinetic (PK) profile consistent with once daily dosing in humans. Taken together, these results suggest vancapticins could be candidates for further development as a promising new therapy for the treatment of antibiotic-resistant Gram-positive bacterial infections.

\section{Results}

Chemical design of a membrane targeting motif. Vancomycin blocks cell wall synthesis by binding to the $C$-terminal tripeptide (L-Lys-D-Ala-D-Ala) of the peptidoglycan precursor Lipid II, preventing cross-linking by bacterial transglycosylases and transpeptidases. A 'back-to-back' dimerisation enhances antimicrobial activity via a surface-templated chelate effect with membranebound Lipid $\mathrm{II}^{22,23}$. In developing a membrane-targeting vancomycin analogue, it was important not to occlude the peptide binding site, nor disrupt interactions at the dimer interface. Previous derivatisations of vancomycin have utilised the vancosamine sugar amine or heptapeptide free carboxyl group; ${ }^{24}$ other modification sites are possible, but more synthetically challenging. In order to attach basic electrostatic effector peptide segments containing lipophilic membrane-insertive elements (MIE), using chemistry compatible with unprotected functionality, we amidated vancomycin with pyridyldithioethylamine, then selectively ligated unprotected basic peptides containing a $C$-terminal Cys residue under mild conditions via disulphide exchange (Fig. 1, Y=S-S; Supplementary Figs. 1-3). The initial membrane targeting glycopeptides employed a lipophilically acylated 16-mer electrostatic effector peptide sequence (EEPS) (GSSKSPSKKKKKKPGD) ${ }^{25}, 26$. These conjugates were fourfold to tenfold more active than vancomycin and daptomycin against MRSA, VISA and multi-drug resistant (MDR) Streptococcus pneumoniae, and more than 100fold more active than vancomycin against VanA Enterococcus faecium (VRE) (Table 1). The corresponding non-ligated lipophilic peptides alone were not active, while equimolar mixtures of the same peptides with vancomycin displayed no synergy (Table 2). For the disulphide-linked series, maximal activity across most strains was observed with a dodecanoyl $(\mathrm{MIE}=\mathrm{nC1} 1 \mathrm{CO})$ insertive element, with potency dropping for both shorter and longer alkyl chain elements (compare 6, 7, 9 in Table 1). A biphenyl insertive element $\mathbf{1 0}$ provided comparable activity to the best alkyl chains. Progressive shortening of the initial 16-mer electrostatic effector

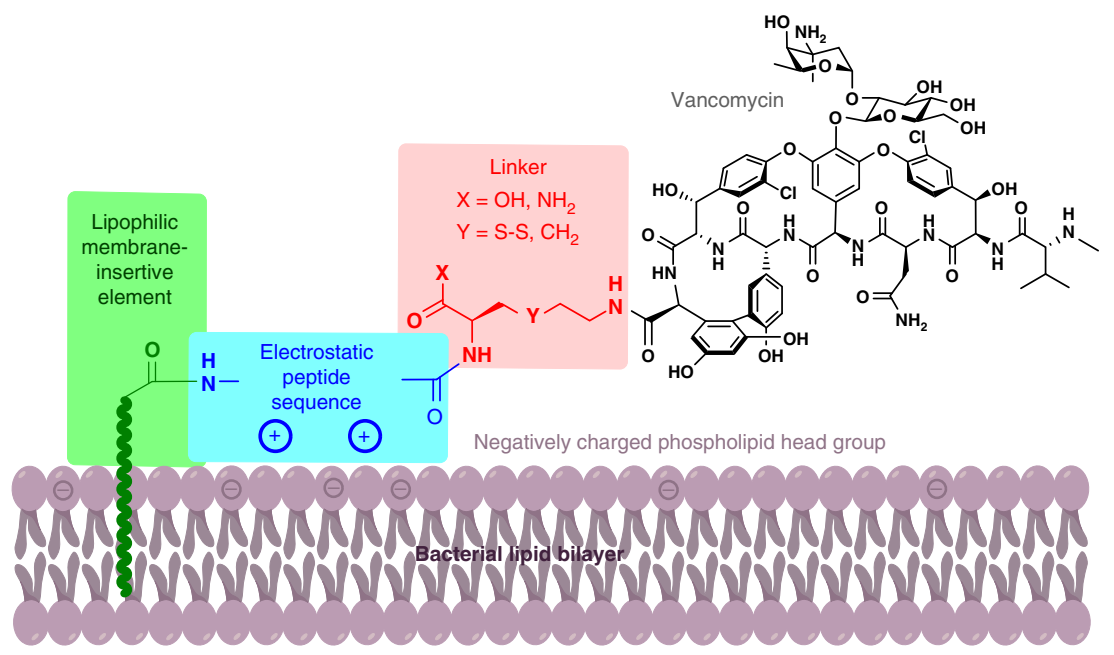

Fig. 1 Structure of lysine-linked and cysteine-linked vancomycin-peptide conjugates. MIE membrane-insertive element, EEPS electrostatic effector peptide sequence 


\section{Table 1 Structure and MIC of key compounds}

\begin{tabular}{|c|c|c|c|c|c|c|c|c|c|}
\hline \multirow[b]{2}{*}{ Id } & \multicolumn{3}{|l|}{ Structure } & \multicolumn{6}{|c|}{$\operatorname{MIC}\left(\mu \mathrm{g} \mathrm{mL}^{-1}\right)$} \\
\hline & MIE $^{\mathbf{a}}$ & EEPS $^{\mathbf{b}}$ & Linker & MRSAC $^{c}$ & $+50 \%$ HS $^{d}$ & VISA $^{e}$ & VRSA $^{f}$ & MDR S.P.g & VRE' \\
\hline 1 & & Vancomycin & & 1 & 1 & 4 & $>64$ & 1 & $>64$ \\
\hline 2 & & Telavancin & & 0.03 & 0.5 & 0.25 & 1 & 0.06 & 2 \\
\hline 3 & & Dalbavancin & & 0.06 & 8 & 1 & 2 & 0.09 & $>8$ \\
\hline 4 & & Daptomycin & & 2 & 3 & 12 & 3 & 2 & 16 \\
\hline 5 & & Oritavancin & & 0.06 & 0.5 & 1 & 0.125 & 0.06 & 0.125 \\
\hline \multicolumn{10}{|c|}{ Cys-based disulphide linker } \\
\hline 6 & $\mathrm{nC9CO}$ & GSSKSPS $(K)_{6} \mathrm{PGD}$ & $\mathrm{C}-\mathrm{NH}_{2}$ & 2.5 & $>8$ & $>8$ & nd & 3 & 1.25 \\
\hline 7 & $\mathrm{nC} 11 \mathrm{CO}$ & GSSKSPS $(K)_{6}$ PGD & $\mathrm{C}-\mathrm{NH}_{2}$ & 0.09 & $>8$ & 1 & nd & 0.06 & 0.02 \\
\hline 8 & $\mathrm{nC} 13 \mathrm{CO}$ & GSSKSPS $(K)_{6} P G D$ & $\mathrm{C}-\mathrm{NH}_{2}$ & 0.5 & $>8$ & 4 & nd & 0.5 & 0.125 \\
\hline 9 & $\mathrm{nC} 15 \mathrm{CO}$ & GSSKSPS $(K)_{6} P G D$ & $\mathrm{C}-\mathrm{NH}_{2}$ & 0.06 & $>8$ & 2 & nd & 0.125 & 8 \\
\hline 10 & $4-P h-B z^{j}$ & GSSKSPS $(K)_{6} \mathrm{PGD}$ & $\mathrm{C}-\mathrm{NH}_{2}$ & 0.19 & nd & 0.19 & nd & 0.25 & 0.06 \\
\hline 11 & $\mathrm{nC} 13 \mathrm{CO}^{\mathrm{i}}$ & GSSKSPSKKKPGD & $\mathrm{C}-\mathrm{NH}_{2}$ & 0.16 & $>8$ & 0.5 & nd & 0.09 & 0.125 \\
\hline 12 & $\mathrm{nC} 13 \mathrm{CO}^{\mathrm{i}}$ & GSSKSPSKKKP & $\mathrm{C}-\mathrm{NH}_{2}$ & 0.09 & $>8$ & 0.5 & nd & 0.06 & 0.007 \\
\hline 13 & $\mathrm{nC} 13 \mathrm{CO}$ & GSKKK & $\mathrm{C}-\mathrm{NH}_{2}$ & 0.011 & 3 & 0.02 & nd & 0.0025 & 0.02 \\
\hline 14 & $\mathrm{nC13CO}{ }^{\mathrm{i}}$ & GSKKK & $\mathrm{C}-\mathrm{OH}$ & $<0.003$ & 0.25 & $<0.003$ & nd & $<0.003$ & 0.09 \\
\hline 15 & $\mathrm{nC13CO}{ }^{\mathrm{i}}$ & KKK & $\mathrm{C}-\mathrm{OH}$ & $<0.003$ & 0.19 & 0.02 & nd & $<0.003$ & 0.02 \\
\hline \multicolumn{10}{|c|}{ Lys-based linker } \\
\hline 16 & $\mathrm{nC} 13 \mathrm{CO}^{\mathrm{i}}$ & GSKKK & $\mathrm{K}-\mathrm{OH}$ & 0.06 & 0.5 & 0.007 & nd & $<0.003$ & nd \\
\hline 17 & $\mathrm{nC} 13 \mathrm{CO}$ & KKK & $\mathrm{K}-\mathrm{OH}$ & $<0.003$ & 0.06 & 0.03 & 0.05 & $<0.003$ & 0.125 \\
\hline 18 & $\mathrm{nC} 10 \mathrm{CO} \mathrm{i}^{\mathrm{i}}$ & KKK & $\mathrm{K}-\mathrm{OH}$ & 0.045 & 0.093 & 0.5 & 0.5 & 0.06 & 1 \\
\hline 19 & $\mathrm{nC} 10 \mathrm{CO}^{\mathrm{i}}$ & KK & $\mathrm{K}-\mathrm{OH}$ & 0.03 & 0.06 & 0.5 & 1 & 0.06 & 6 \\
\hline 20 & $\mathrm{nC10CO}$ & - & $\mathrm{K}-\mathrm{OH}$ & 0.125 & 6 & 1.5 & nd & 0.19 & $>8$ \\
\hline 21 & $\mathrm{nC10CO}{ }^{\mathrm{i}}$ & $\mathrm{KK}$ & $\mathrm{K}-\mathrm{NH}_{2}$ & 0.007 & 0.06 & 0.06 & nd & 0.015 & 2 \\
\hline 22 & $\mathrm{nC10CO}{ }^{\mathrm{i}}$ & KK & K-NHMe & 0.015 & 0.06 & 0.125 & 0.5 & 0.015 & 4 \\
\hline 23 & POB2K $K^{k}$ & KK & $\mathrm{K}-\mathrm{OH}$ & $<0.003$ & 0.25 & 0.5 & nd & $<0.003$ & 4 \\
\hline 24 & POB2K ${ }^{k}$ & KK & K-NHMe & $<0.003$ & 0.06 & 0.125 & 0.08 & $<0.003$ & 0.5 \\
\hline 25 & $A C^{\prime}$ & KK & $\mathrm{K}-\mathrm{OH}$ & 4 & 4 & $>8$ & $>8$ & 4 & $>8$ \\
\hline \multicolumn{10}{|c|}{ 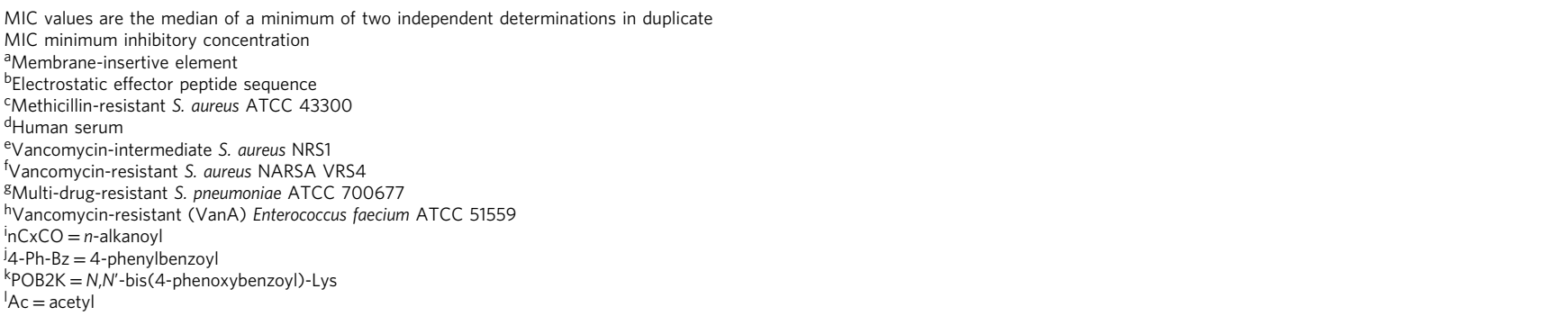 } \\
\hline
\end{tabular}

sequence did not compromise activity (11-15), and led to improved activity for a minimal basic KKK motif.

Linker strategy leads to improvements in metabolic stability. Initial in vivo studies indicated that the disulphide-linked conjugates possessed a very short half-life, consistent with in vitro studies showing instability in human plasma (Supplementary Table 2) or in the presence of physiological concentrations of glutathione (Supplementary Fig. 4). We therefore replaced the Cys-derived linker with a stable attachment through the side chain of Lys (Fig. 1, $\mathrm{Y}=\mathrm{CH}_{2}$, Supplementary Figs. 5-9), with the new compounds maintaining the desirable activity of the disulphide-linked pilot series. The best compounds were 20-fold to more than 100 -fold more potent than vancomycin or daptomycin against MRSA, and significantly more active against VISA, VRSA and VRE (Tables 1 and 3), with inhibitory activity as good, or better than, recently approved glycopeptide antibiotics telavancin, dalbavancin and oritavancin. They showed similar high levels of potency (e.g. MIC $\leq 0.03 \mu \mathrm{g} \mathrm{mL}^{-1}$ ) against other Gram-positive strains, including daptomycin-resistant MRSA, MDR S. pneumoniae, S. pyogenes and S. epidermidis, but were inactive against Gram-negative Escherichia coli (data not shown). Importantly, these new compounds were stable when exposed to plasma (Supplementary Table 2) and glutathione (Supplementary Fig. 4), and were resistant to microsomal metabolism (Supplementary Table 3).

Vancapticins possess promising drug-like properties. The lysine-linked compounds possessed low cytotoxicity against human cell lines (HepG2 and HEK293, with CC $_{50}$ over 1000-fold higher than the MIC for most compounds, even when tested with cells grown in only $1 \%$ serum to maximise cell sensitivity and availability of free compound) (Supplementary Table 4), and demonstrated minimal haemolysis of human erythrocytes in whole blood (most compounds were still non-haemolytic at 1600 $\mu \mathrm{g} \mathrm{mL}^{-1}$, over 10,000-fold higher than the MIC) (Supplementary Table 5). Antibiotic activity was measured both in the absence and presence of $50 \%$ human serum (Table 1), with the seruminduced reversal in activity (varying from 1-fold to 100-fold) used as a surrogate to estimate of the extent of protein binding. The compounds retained activity in the presence of an artificial lung surfactant ( $1 \%$ or $5 \%$ Survanta (Beractant), Supplementary Table 6), which reduces the activity of some antibiotics such as daptomycin $^{27}$ and makes them unsuitable for the treatment of lung infections. Vancapticin $\mathbf{2 4}$ was shown to be slowly bactericidal in a similar manner to vancomycin (Fig. 2). 
Table 2 Comparison of MIC activity of MIE-EEPS peptide vs. MIE-EEPS peptide-vancomycin conjugate vs. admixture of MIEEEPS peptide plus vancomycin

\begin{tabular}{|c|c|c|c|c|c|c|c|}
\hline \multicolumn{2}{|l|}{ Structure } & \multicolumn{3}{|c|}{ MIC $\left(\mu \mathrm{g} \mathrm{mL}^{-1}\right)$ S. aureus MRSA ATCC 43300} & \multicolumn{3}{|c|}{ MIC $\left(\mu \mathrm{g} \mathrm{mL}^{-1}\right)$ E. faecium MDR VanA ATCC 51559} \\
\hline $\begin{array}{l}\text { MIE-EEPS } \\
\text { peptide }\end{array}$ & Vanc conj. & $\begin{array}{l}\text { MIE-EEPS } \\
\text { peptide }^{b}\end{array}$ & $\begin{array}{l}\text { MIE-EEPS peptide/ } \\
\text { vanc mixture (1:1) }\end{array}$ & Vanc conj. & $\begin{array}{l}\text { MIE-EEPS } \\
\text { peptide }^{b}\end{array}$ & $\begin{array}{l}\text { MIE-EEPS peptide/vanc } \\
\text { mixture (1:1) }\end{array}$ & Vanc conj. \\
\hline Vanc & 1 & & 1 & & & $>64$ & \\
\hline $12 a^{d}$ & 12 & $>8$ & 4 & 0.09 & $>8$ & 4 & 0.007 \\
\hline $13 a^{e}$ & 13 & $>8$ & 4 & 0.011 & $>8$ & 4 & 0.02 \\
\hline $14 a^{f}$ & 14 & $>8$ & 4 & $<0.003$ & $>8$ & 4 & 0.09 \\
\hline
\end{tabular}

MIC measurements are the median of a minimum of two independent determinations in duplicate

a Membrane-insertive element-Electrostatic effector peptide sequence

bote that the concentration of peptide on a molar basis is >twofold higher than when contained in the peptide-vancomycin derivative

${ }^{\mathrm{C}} 8 \mathrm{a}=n \mathrm{n} 13 \mathrm{CO}-\mathrm{GSSKSPSKKKKKKPGD-Cys-NH2}$

${ }^{d} 12 \mathrm{a}=n C 13 C O-G S S K S P S K K K P-C y s-N H 2$

$\mathrm{e}_{13} \mathrm{a}=n \mathrm{C} 13 \mathrm{CO}-\mathrm{GSKKK}-\mathrm{Cys}-\mathrm{NH} 2$

${ }^{\mathrm{f}} 14 \mathrm{a}=n \mathrm{nC13CO}-\mathrm{GSKKK}-\mathrm{Cys}-\mathrm{OH}$

$\mathrm{g}_{15} \mathrm{a}=n \mathrm{C} 13 \mathrm{CO}-\mathrm{KKK}-\mathrm{Cys}-\mathrm{OH}$

It is important that new antibiotics are not susceptible to innate or induced resistance. Compound 19 showed a low resistance frequency (a measure of the existing propensity for resistance) of $9.4 \times 10^{-10}$ against MRSA (ATCC 43300) (Supplementary Table 7). Both 17 and 24 induced low levels of resistance compared to daptomycin when MRSA (ATCC 43300) cultures were serially cultured over 20 days in the presence of increasing sub-lethal antibiotic concentrations (Fig. 3).

Structure-activity relationships. Structure-activity relationship studies using the stable linker series focused on variations in the insertive element and basic EEPS peptides. Subtle variations were observed between bacteria, with $S$. aureus and $S$. pneumoniae reaching maximal inhibition with dodecanoic acid (MIE= nC11CO), while E. faecium exhibited greater sensitivity toward longer alkyl groups $>\mathrm{C} 12$ (Table 3). However, these longer alkyl elements led to both increasing serum reversal and cytotoxicity, with undecanoic acid $(\mathrm{MIE}=\mathrm{nC} 10 \mathrm{CO})$ providing an optimum compromise. In contrast, removal of the lipidic component altogether diminished activity (compare 25 vs. 19) highlighting the importance of the insertive element for antimicrobial potency. Variation of the charged region from zero to three Lys residues (18-20) (Table 1) led to minor improvements in serum-free antibacterial activity, but the increasing charge caused variations in serum reversal and increased potency against E. faecium, particularly compared to $\mathbf{2 0}$ with no basic residue. A dibasic sequence (KK) was selected as optimum. Enantiomeric all $\mathrm{D}$-amino acid effector sequences or linkers were equipotent with the natural L-amino acids, as were replacements of Lys with Orn or Dab, suggesting that no chiral molecular recognition was involved (Table 3 ).

Demonstration of efficacy against MRSA and MDR S. pneumoniae. We next examined the PK profiles of compounds 18, 19, 21 and 24 in mice (Fig. 4). When compared to the murine profiles of daptomycin ${ }^{28}$ and telavancin ${ }^{29}$, our compounds exhibited profiles consistent with extrapolated once-daily dosing in man, representing a significant advantage over the twice daily dosing most commonly used for vancomycin. In mouse plasma, compound levels were maintained at concentrations above the MRSA MIC (determined in the presence of serum) for over $12 \mathrm{~h}$ following a single $10 \mathrm{mg} \mathrm{kg}^{-1}$ subcutaneous (SC) dose (Fig. 4, Supplementary Tables 8 and 9). While the PK/PD driver for vancomycin is now believed to be the area under the unbound drug concentration-time curve [fAUC]/MIC, historically the percentage of a 24-h time period that the unbound drug concentration exceeds the MIC [ $\left.f T_{>\mathrm{MIC}}\right]$ was initially reported to be a better predictor of the antibacterial effect so is still useful as an approximation $^{30}$.

The new compounds showed potent bactericidal efficacy in a neutropenic mouse thigh infection model against MRSA. A single $25 \mathrm{mg} \mathrm{kg}^{-1}$ subcutaneous (SC) dose of 19 was equivalent to a single $200 \mathrm{mg} \mathrm{kg}^{-1}$ dose of vancomycin, with a 6-log reduction compared to the saline control at $24 \mathrm{~h}$ (Fig. 5a). Activity was still maintained at $5 \mathrm{mg} \mathrm{kg}^{-1}$ for 19 , while vancomycin was almost inactive at $25 \mathrm{mg} \mathrm{kg}^{-1}$. Highly protein bound 24 was less effective, but other analogues such as $\mathbf{2 1}$ were equally active. Both 19 and 24, when tested in an alternate lung infection model using intratracheal administration of a lethal dose of $S$. pneumoniae, resulted in $100 \%$ survival after 10 days (Fig. 5b). The results from the pneumonia model were consistent with in vitro MIC testing that showed activity was maintained in the presence of artificial lung surfactant, in contrast to the loss of activity observed with daptomycin, which is ineffective at treating pneumonia ${ }^{31}$. Finally, 19 and 24 were tested in an intra-peritoneal (IP) infection model using bioluminescent methicillin-sensitive S. aureus (MSSA) Xen29 , with imaging at $9 \mathrm{~h}$ post infection again showing good efficacy for 19 , but a reduced activity for 24 (Fig. 5c-e).

Assessment of Lipid II binding mechanism of action. Vancomycin acts by inhibiting the transpeptidase step of peptidoglycan synthesis, although there is also evidence of blocking the previous transglycosylase step ${ }^{32}$. Kahne and co-workers have reported that vancomycin group antibiotics with lipophilic substituents (e.g. a biphenyl group) differ from vancomycin by acting primarily via transglycosylase inhibition ${ }^{33}$. The remarkable activity of our compounds could be due to a number of factors: (i) an increased affinity for the target terminal D-Ala-D-Ala dipeptide of Lipid II, (ii) enhanced dimerisation leading to higher avidity for membrane-bound Lipid $\mathrm{II}^{34}$, (iii) an additional or different mode of action or target than vancomycin (such as membrane permeabilisation), and/or (iv) membrane localisation resulting in an enhanced drug concentration at the membrane surface, which could serve to enhance any of the above.

Compounds 17 and 24 inhibited peptidoglycan formation in a cell free radiolabelled synthesis assay that monitors the incorporation of ${ }^{14} \mathrm{C}$-labelled $\mathrm{N}$-acetylglucosamine $\left[{ }^{14} \mathrm{C}\right.$-GlcNAc] into Lipid II and then into peptidoglycan, with Lipid II accumulating at tenfold lower concentration of compound compared to vancomycin (Figs. 6a-c). A competitive ligand 


\section{Table 3 Structure activity relationships of carbon-linked vancapticins}

\begin{tabular}{|c|c|c|c|c|c|c|c|c|c|c|}
\hline \multirow[b]{2}{*}{ Id } & \multicolumn{4}{|l|}{ Structure } & \multicolumn{6}{|c|}{ MIC ( $\left.\mu \mathrm{g} \mathrm{mL}^{-1}\right)$} \\
\hline & MIE & EEPS & Linker & MRSA $^{a}$ & MSSA $^{\mathbf{b}}$ & $+50 \% \mathrm{HS}^{\mathrm{c}}$ & VISA $^{d}$ & VRSA $^{\mathbf{e}}$ & MDR SPf & VREg \\
\hline 1 & & Vancomycin & & 1 & 1 & 1 & 4 & $>64$ & 1 & $>64$ \\
\hline 2 & & Telavancin & & 0.06 & nd & 0.5 & 0.25 & 1 & 0.06 & 2 \\
\hline 3 & & Dalbavancin & & 0.03 & $\leq 0.016$ & 8 & 1 & 16 & 0.09 & $>8$ \\
\hline 4 & & Daptomycin & & 2 & 1 & 3 & 12 & 3 & 2 & 16 \\
\hline 5 & & Oritavancin & & 0.06 & $\leq 0.016$ & 0.5 & 1 & 0.125 & 0.06 & 0.125 \\
\hline \multicolumn{11}{|c|}{ Effect of chirality-EEPS and linker } \\
\hline 24 & POB2K $K^{h}$ & KK & $\mathrm{K}-\mathrm{NHMe}$ & $<0.003$ & $\leq 0.016$ & 0.06 & 0.125 & 0.08 & $<0.003$ & 0.5 \\
\hline 25 & POB2K ${ }^{h}$ & kk & $\mathrm{K}-\mathrm{NHMe}$ & 0.0007 & nd & 0.5 & 0.125 & nd & 0.015 & 2 \\
\hline 26 & POB2K $K^{h}$ & kK & $\mathrm{K}-\mathrm{NHMe}$ & $<0.003$ & nd & 0.25 & 0.19 & nd & $<0.003$ & 1.5 \\
\hline 27 & POB2K & $\mathrm{Kk}$ & $\mathrm{K}-\mathrm{NHMe}$ & 0.03 & nd & 0.25 & 0.75 & nd & 0.04 & 10 \\
\hline 28 & POB2K ${ }^{h}$ & $\mathrm{KK}$ & k-NHMe & $<0.003$ & nd & 0.06 & 0.125 & nd & 0.015 & 0.75 \\
\hline \multicolumn{11}{|c|}{ Effect of side chain length-EEPS and linker } \\
\hline 24 & POB2K ${ }^{h}$ & $\mathrm{KK}$ & K-NHMe & $<0.003$ & nd & 0.06 & 0.125 & 0.08 & $<0.003$ & 0.5 \\
\hline 27 & POB2K ${ }^{h}$ & K-Dap & K-NHMe & 0.0045 & nd & 0.375 & 0.0925 & nd & 0.016 & 1.5 \\
\hline 28 & POB2K & Dap-K & K-NHMe & 0.0045 & nd & 0.25 & 0.155 & nd & 0.011 & 0.75 \\
\hline 29 & POB2K ${ }^{h}$ & Dap-Dap & K-NHMe & 0.0045 & nd & 0.5 & 0.0925 & nd & 0.0085 & 0.75 \\
\hline 30 & POB2K ${ }^{h}$ & K-Dab & K-NHMe & $<0.003$ & nd & 0.06 & 0.0925 & nd & $<0.003$ & 0.75 \\
\hline 31 & POB2K ${ }^{h}$ & Dab-K & K-NHMe & $<0.003$ & nd & 0.045 & 0.0925 & nd & $<0.003$ & 0.375 \\
\hline 32 & POB2K & K-Orn & K-NHMe & $<0.003$ & nd & 0.19 & 0.0375 & nd & $<0.003$ & 1 \\
\hline 33 & POB2K & Orn-K & $\mathrm{K}-\mathrm{NHMe}$ & $<0.003$ & nd & 0.125 & 0.125 & nd & 0.007 & 1.5 \\
\hline 34 & POB2K ${ }^{h}$ & Orn-Orn & $\mathrm{K}-\mathrm{NHMe}$ & $<0.003$ & nd & 0.25 & 0.0185 & nd & $<0.003$ & 0.5 \\
\hline 35 & POB2K ${ }^{h}$ & $\mathrm{KK}$ & Orn-NHMe & $<0.003$ & nd & 0.16 & 0.25 & nd & 0.005 & 1.25 \\
\hline \multicolumn{11}{|c|}{ Effect of MIE on activity } \\
\hline 36 & nC9CO-i & KKK & $\mathrm{K}-\mathrm{OH}$ & 0.06 & nd & 0.06 & 0.75 & 0.75 & 0.06 & 8 \\
\hline 18 & nC10CO- & KKK & $\mathrm{K}-\mathrm{OH}$ & 0.045 & nd & 0.093 & 0.5 & 0.5 & 0.06 & 1.03 \\
\hline 37 & nC11CO- & KKK & $\mathrm{K}-\mathrm{OH}$ & 0.005 & nd & 0.03 & 0.06 & 0.75 & $<0.003$ & 0.5 \\
\hline 38 & $\mathrm{nC} 12 \mathrm{CO}-$ & KKK & $\mathrm{K}-\mathrm{OH}$ & $<0.003$ & nd & 0.045 & 0.03 & nd & $<0.003$ & 0.1875 \\
\hline 17 & nC13CO- & KKK & $\mathrm{K}-\mathrm{OH}$ & $<0.003$ & $\leq 0.016$ & 0.06 & 0.03 & 0.045 & $<0.003$ & 0.125 \\
\hline 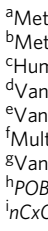 & $\begin{array}{l}\text {-resistant } S . \text { a } \\
\text { n-sensitive S. a } \\
\text { erum } \\
\text { cin intermediat } \\
\text { cin-resistant S. } \\
\text {-resistant } S \text {. pn } \\
\text { cin-resistant ( } \\
N^{\prime} \text {-bis } 4 \text {-phen }\end{array}$ & $\begin{array}{l}\text { ATCC } 43300 \\
\text { s ATCC } 29213 \\
\text { aureus NRS1 } \\
\text { us NARSA VRS4 } \\
\text { miae ATCC 70067 } \\
\text { ) Enterococcus faec } \\
\text { enzoyl)-Lys } \\
\text { ermined. MIC mea }\end{array}$ & CC 51559 & & & & & & & \\
\hline
\end{tabular}
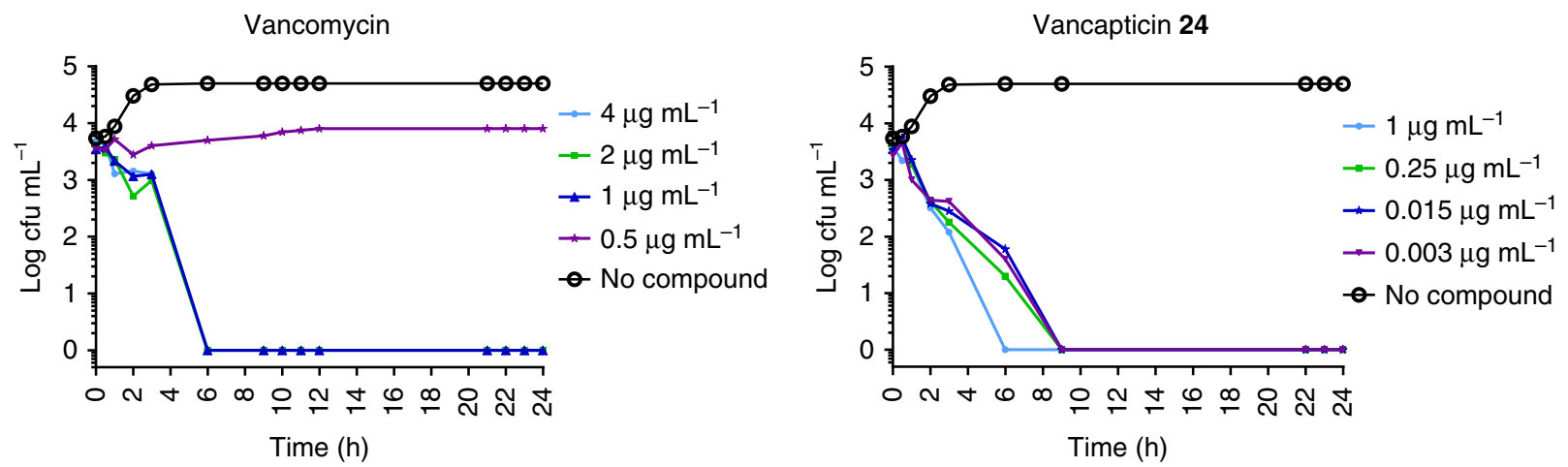

Fig. $\mathbf{2}$ Time kill assay. Bactericidal activity of vancomycin $\mathbf{1}$ and vancapticin $\mathbf{2 4}$ against S. aureus ATCC 43300 as measured by agar plate dilution colony measurement of wells from broth microdilution MIC measurement over time. Data are $n=1$

antagonism assay (Fig. 6e), in which the MIC was tested in the presence of a Lipid II binding site competitor, Ac-Lys(Ac)-D-AlaD-Ala $\left(\mathrm{Ac}_{2} \mathrm{Kaa}\right)$, required a 100 -fold molar excess of $\mathrm{Ac}_{2} \mathrm{Kaa}$ to ablate the activity of vancomycin. In contrast, the new compounds required over 10,000-fold molar excess to neutralise antibiotic action, also confirming that the new analogues still targeted Lipid II and peptidoglycan synthesis (Fig. 6e, Supplementary Table 10). Isothermal titration calorimetry (ITC) assessing glycopeptide binding to the C-terminal tri-peptide or penta-peptide components of Lipid II showed overall similar binding as vancomycin, with increased enthalpy offset by increased entropy (Fig. 6d, Supplementary Fig. 11). The 

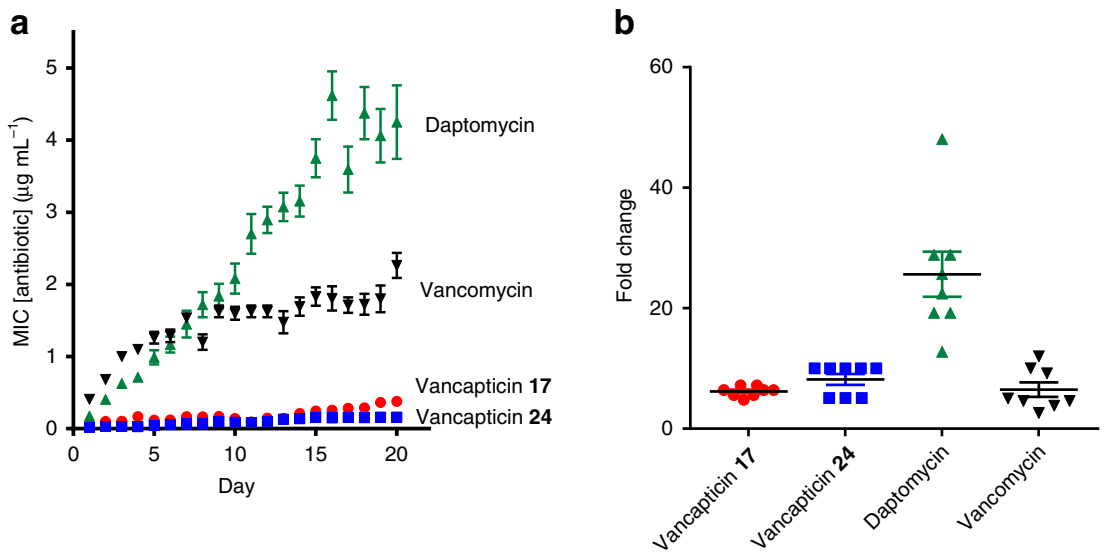

Fig. 3 Resistance induction. a Average daily MIC for MRSA (ATCC 43300) grown with increasing sub-lethal concentrations of vancomycin, daptomycin, compound $\mathbf{1 7}$ and compound $\mathbf{2 4}$ over 20 days of bacterial growth. $\mathbf{b}$ The corresponding overall fold-increase in MRSA MIC for the four compounds. Data are mean \pm SEM for $n=8$
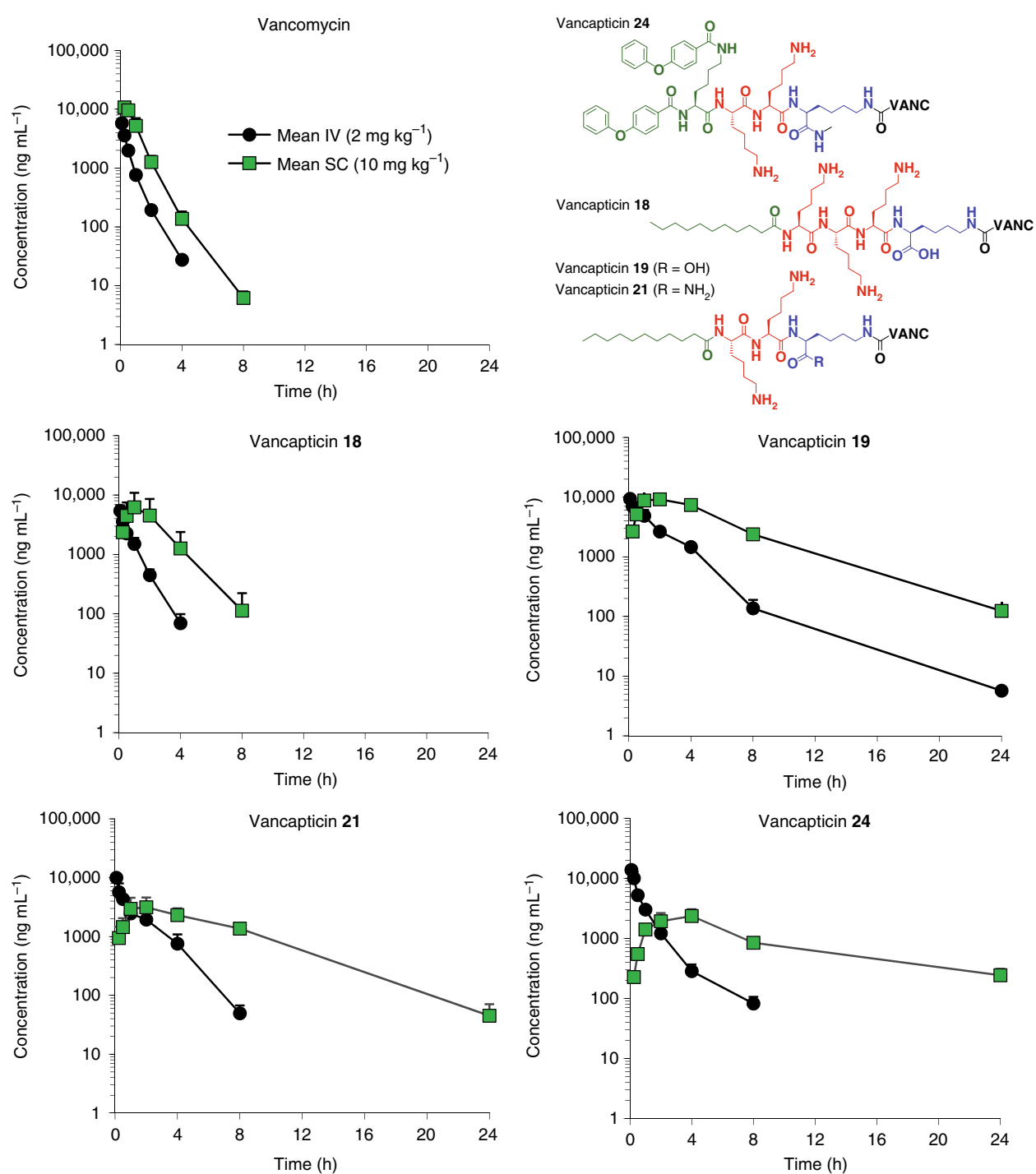

Fig. 4 Mouse PK. Pharmacokinetic profiles with plasma concentrations of vancomycin and compounds 18, 19, 21 and 24 dosed at 2 mg kg-1 intravenously (IV) or $10 \mathrm{mg} \mathrm{kg}^{-1}$ subcutaneously (SC) in mice; serial sampling. Data are mean + S.D. for $n=3$. See Supplementary Tables 8 and 9 for individual mouse data and calculated parameters 
a

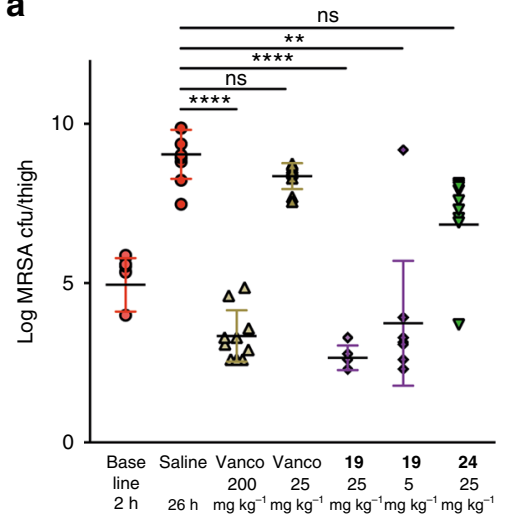

b

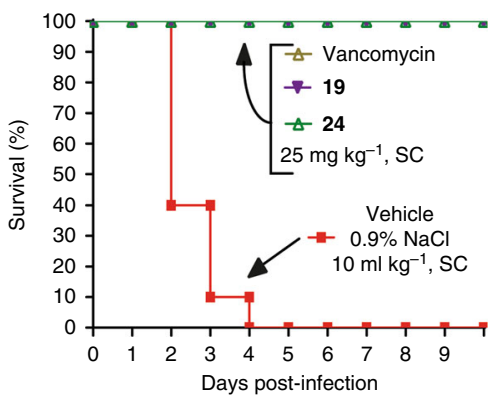

c

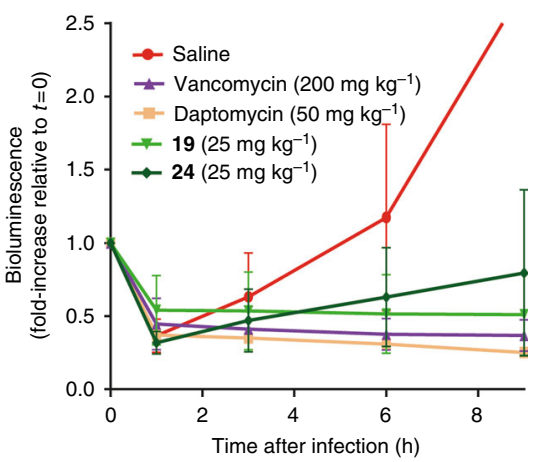

d

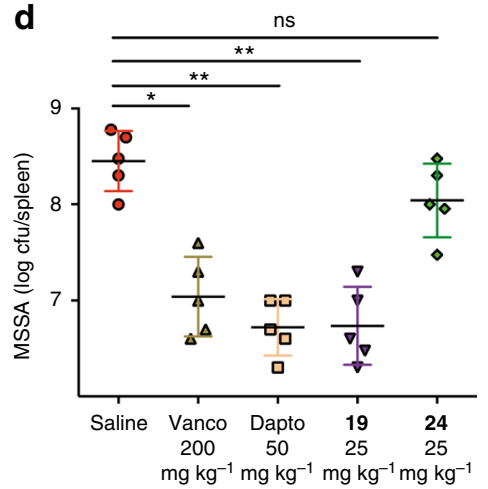

e
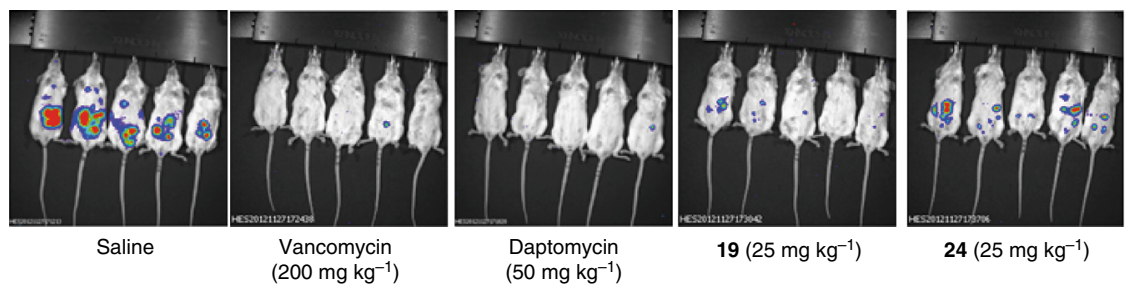

$24\left(25 \mathrm{mg} \mathrm{kg}^{-1}\right)$

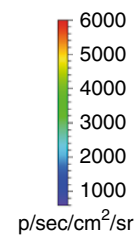

Fig. 5 Mouse efficacy models. a MRSA thigh infection model. Colony forming units (CFU) in neutropenic mice infected in each thigh with MRSA, followed $2 \mathrm{~h}$ later by a single subcutaneous dose of antibiotic at concentrations indicated, with sacrifice and bacterial load determination in homogenised thighs at $24 \mathrm{~h}$ post treatment ( $26 \mathrm{~h}$ post infection): $n=10$ (five mice per group, two thighs per mouse; errors are mean $\pm \mathrm{SEM}$ ). A significant difference was found between saline at $26 \mathrm{~h}$ and vancomycin 1 at $200 \mathrm{mg} \mathrm{kg}^{-1}$ ( $p<0.0001$ ), and vancapticin 19 at both $25 \mathrm{mg} \mathrm{kg}^{-1}(p<0.0001)$ and $5 \mathrm{mg} \mathrm{kg}^{-1}$ ( $p=0.0011$ ). No statistical difference was found for vancomycin $\mathbf{1}$ at $25 \mathrm{mg} \mathrm{kg}^{-1}$ or vancapticin $\mathbf{2 4}$ at $25 \mathrm{mg} \mathrm{kg}^{-1}$ compared to saline. Vancapticin $\mathbf{1 9}$ at $25 \mathrm{mg} \mathrm{kg}^{-1}$ also showed a significant reduction compared to the initial $t=2 \mathrm{~h}$ baseline inoculum $(p=0.0014)$ whereas vancomycin $\mathbf{1}$ at $200 \mathrm{mg} \mathrm{kg}^{-1}$ was not statistically significant. Statistical analysis done using Graph Pad, 1-way ANOVA, Bonferroni post-test. b $S$. pneumoniae lung infection LD $_{90}$. Survival of healthy mice infected with a lethal intratracheal dose of S. pneumoniae ATCC6301 followed $2 \mathrm{~h}$ later by a single subcutaneous dose of antibiotic at $25 \mathrm{mg} \mathrm{kg}^{-1}$ ( $n=10$ mice per group). c-e Bioluminescent MSSA intraperitoneal model. Neutropenic mice were injected intraperitoneally with $2.5 \times 10^{7}$ CFU bioluminescent MSSA Xen-29 (possessing a stable copy of the Photorhabdus luminescens lux operon on the bacterial chromosome) then treated after $0.5 \mathrm{~h}$ with subcutaneous doses of saline, $200 \mathrm{mg} \mathrm{kg}{ }^{-1} \mathrm{vancomycin}$, $50 \mathrm{mg} \mathrm{kg}^{-1}$ daptomycin, $25 \mathrm{mg} \mathrm{kg}^{-1} \mathbf{1 9}$ or $25 \mathrm{mg} \mathrm{kg}^{-1} \mathbf{2 4}$ ( $n=5$ mice per group). c Changes in total flux levels. Variations in bioluminescence were measured at $T$ $=0,1,3,6$ and $9 \mathrm{~h}$, quantified with the IVIS Living Image software where the total flux (number of photons/second) was calculated by a user defined region of interest (ROI) covering the infection sites. The saline treated group showed a large increase in the total flux, particularly after $3 \mathrm{~h}(T=3 \mathrm{~h})$. Daptomycin, vancomycin and $\mathbf{1 9}$ treated groups showed a progressive reduction in the bioluminescence signal $1 \mathrm{~h}$ after inoculation, while the signal detected from $\mathbf{2 4}$ increased slightly. All antibiotic administered groups showed reduced bioluminescence signal at $T=9 \mathrm{~h}$ compared to immediately after inoculation ( $p<0.001$ for all groups; errors are mean \pm S.D). $\mathbf{d}$ Changes in CFU per spleen after $9 \mathrm{~h}$. Individual spleens were homogenised and diluted for plating. The calculated CFU/spleen counts for five mice are presented, along with the mean (black bar); errors are mean \pm S.D. A significant difference was found between saline and vancomycin $\mathbf{1}$, daptomycin 4 and compound $\mathbf{1 9}$ ( $p<0.001$ for all groups). No statistical difference was found for $\mathbf{2 4}$ compared to saline, while this compound was found statistically less efficacious than 1 ( $p<0.01), \mathbf{4}(p<0.001)$, and $19(p<0.001)$. Statistical analysis done using Graph Pad, 1-way ANOVA, Bonferroni post-test. e Bioluminescent images at $T=9 \mathrm{~h}$. Bioluminescent imaging of infected mice at $T=9 \mathrm{~h}$ using Xenogen IVIS-200 Optical In Vivo Imaging System (PerkinElmer)

propensity of compounds to dimerise (also determined by ITC) was found to be similar to that for vancomycin (Supplementary Table 11, Supplementary Fig. 12), and increased in the presence of ligand. Hence, neither enhanced ligand binding nor dimerisation was responsible for the improved potency.
Assessment of membrane binding and disruption mechanism of action. Increased membrane association of the new compounds 17 and 24 compared to vancomycin was supported by surface plasmon resonance (SPR) studies. There was a propensity to bind more strongly to anionic (dimyristoyl-L- $\alpha$-phosphatidyl- 

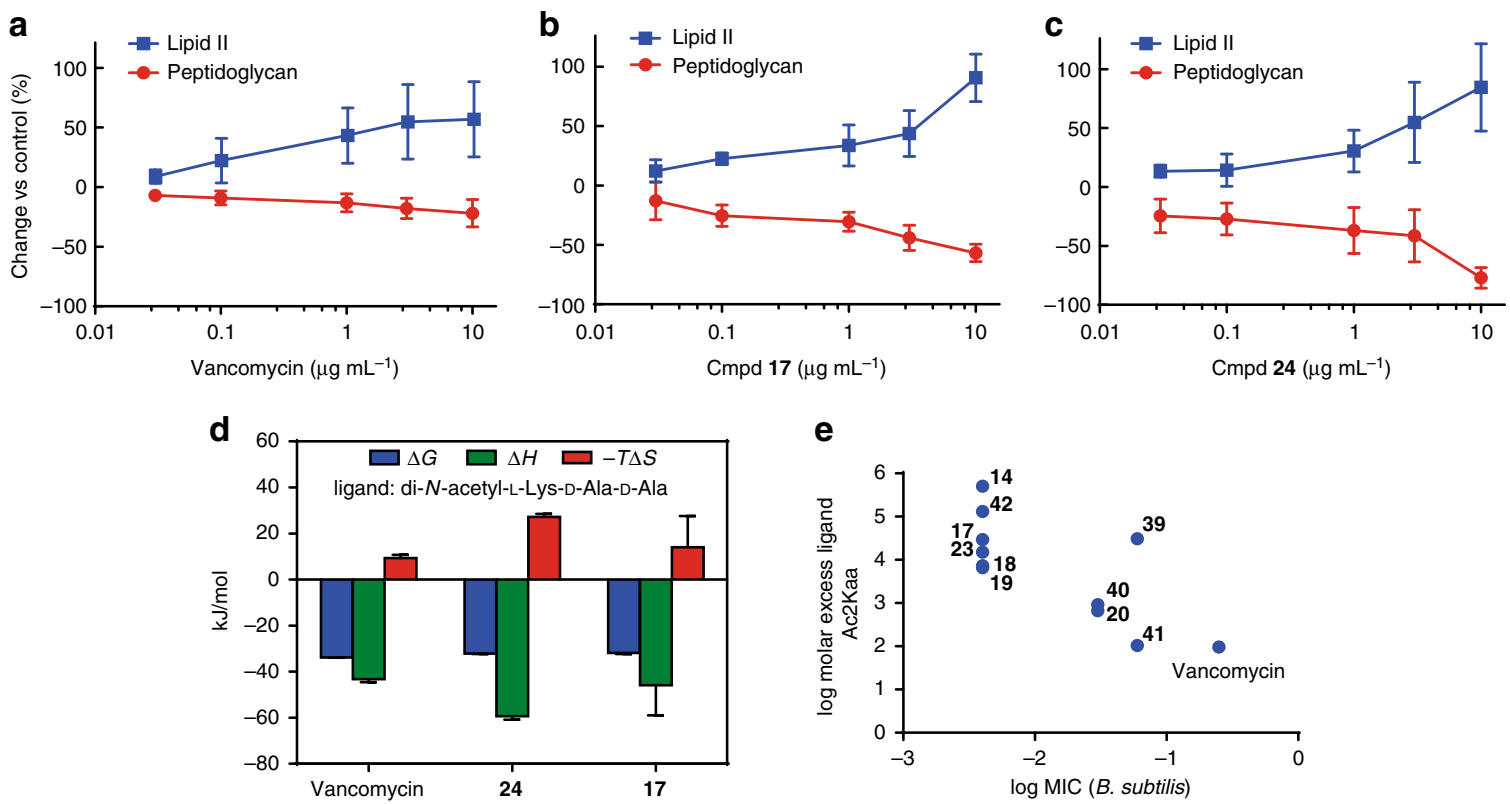

Fig. 6 Lipid II binding effects. a-c Accumulation of Lipid II (blue) and \% inhibition of peptidoglycan synthesis (red) measured in cell-free assay system using ${ }^{14}$ C-labelled Lipid II precursor as a function of antibiotic concentration (errors are mean \pm S.D, $n=3$ ) for (a) vancomycin, (b) Cmpd 17 and (c) Cmpd 24. d ITC data for binding to AC-Lys(AC)-D-Ala-D-Ala (errors are mean \pm S.D, $n=3$ ). e molar excess of ligand AC-Lys(AC)-D-Ala-D-Ala (KDADA) required to antagonise antibacterial activity of compounds against B. subtilis (ATCC 6633) compared to the MIC of compounds

L-glycerol, DMPG) over zwitterionic (dimyristoyl-L- $\alpha$-phosphatidylcholine, DMPC) lipid bilayers (Fig. 7a). To discount the possibility that enhanced antimicrobial activity resulted from non-specific membrane-based perturbation effects similar to those induced by cationic antimicrobial peptides ${ }^{35}$, membrane effects of the new compounds were assessed. Aggregation was discounted as a source of membrane activity as the critical micelle concentration (CMC) was found to exceed $100 \mu \mathrm{M}$ for selected compounds 17, 19 and 23. Furthermore, compounds were generally non-haemolytic against human erythrocytes in whole blood at $1600 \mu \mathrm{g} \mathrm{mL} \mathrm{L}^{-1}$, with any haemolysis observed not correlating with lipophilicity (Fig. 7b and Supplementary Table 5).

Evidence for membrane perturbation was obtained in the presence of membrane-selective fluorescent probes. First, we employed the membrane potential-sensitive cationic fluorescent probe 3,3'-dipropylthiadicarbocyanine iodide [diSC3(5)], which is prevented from partitioning to the surface of polarised cells during disruption of membrane potential, causing dye release into the media ${ }^{36}$. Here, analogues 17 and 24 were observed to dissipate the membrane potential of MRSA (ATCC 43300) to a similar or greater degree than the control antibiotic oritavancin $5^{37}, 38$, as measured by the fluorescence output of diSC3(5) (Fig. 7c). All compounds were dosed at $16 \mu \mathrm{g} \mathrm{mL}^{-1}$, equating to a concentration approximately 16-fold above their MIC for 5, 17 and 24 (Note that membrane permeabilisation studies were conducted in polystyrene plates without polysorbate- 80 additive to avoid assay interferences; under these conditions the MIC for 5, 17 and $24=1-2 \mu \mathrm{g} \mathrm{mL}{ }^{-1}$-Supplementary Table 12). The effect was less pronounced for compound 19 despite a higher MIC-fold exposure ( 128-fold MIC), whereas vancomycin, daptomycin and dalbavancin showed no effect under the conditions of the assay. Similar effects were observed against MSSA (ATCC 29213) (Supplementary Fig. 13).

Additional evidence for membrane perturbation was obtained with the membrane impermeable dye propidium iodide (PI), which stains nuclear chromatin upon cell membrane disruption, resulting in fluorescence enhancement ${ }^{39}$. To this end, MRSA (ATCC 43300) was incubated with selected antibiotic compounds at $16 \mu \mathrm{g} \mathrm{mL}^{-1}$ for $1 \mathrm{~h}(\sim 16$-fold MIC for compounds 17, 24, oritavancin, dalbavancin and vancomycin in polystyrene plates) followed by exposure to propidium iodide (Fig. 7d). Again, compounds 17 and 24 elicited a response with comparable fluorescence intensity to oritavancin ${ }^{37,38}$. Daptomycin ${ }^{40}$ caused approximately 4-6-fold higher fluorescence than oritavancin or 17. In contrast, compound 19, vancomycin and dalbavancin showed little to no effect in this membrane permeabilisation assay. A similar trend was observed against MSSA (ATCC 29213) (Supplementary Fig. 14).

\section{Discussion}

Whilst there is a current perception that Gram-positive antibiotics are less urgently required than Gram-negative therapies, in reality the number of drug-resistant Gram-positive infections, and resulting deaths, far outnumber those from resistant Gramnegative bacteria ${ }^{1}$. Over the past four decades the rational improvement of existing classes of antibiotics has proven to be a very successful strategy. Vancomycin is a logical candidate for improvement via specific membrane-targeting, given its mode of action and the length of time it took (more than 20 years) for significant clinical resistance to arise.

Membrane-ligand interactions are an underexplored area of drug design. We created a series of membrane-targeted vancomycin derivatives with significantly improved activity against a range of Gram-positive bacteria, including vancomycin-resistant strains. The modular nature of their structure (Fig. 1), with a lipophilic group (MIE) designed to insert in the membrane, a positively charged peptide (EEPS) for electrostatic interaction with the overall negative surface charge of bacterial membranes, and a linker for attachment to the C-terminal carboxyl group of vancomycin, provided a platform to readily produce multiple derivatives using solid phase peptide synthesis. A series of structure-activity relationship studies resulted in promising compounds with potent in vitro activity, often more than 100fold more active than vancomycin (Tables 1 and 3). Both MIE and EEPS components were required for enhanced activity. 
a

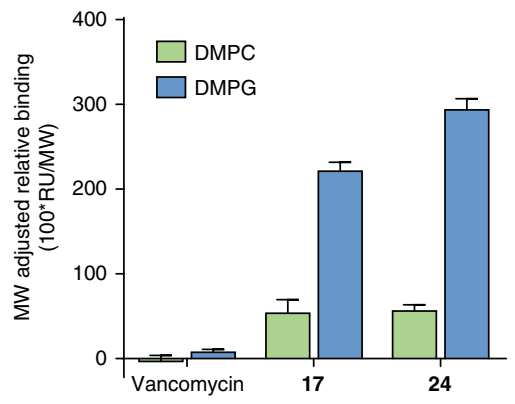

C

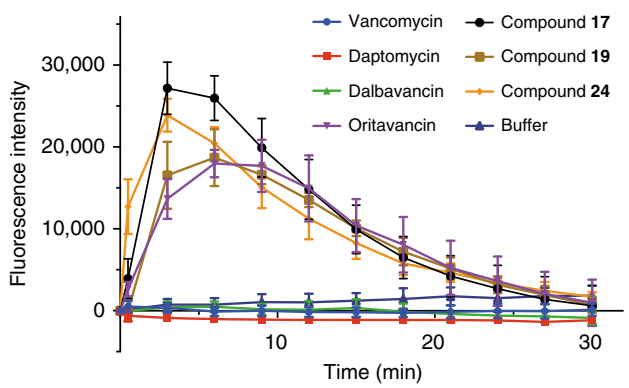

b

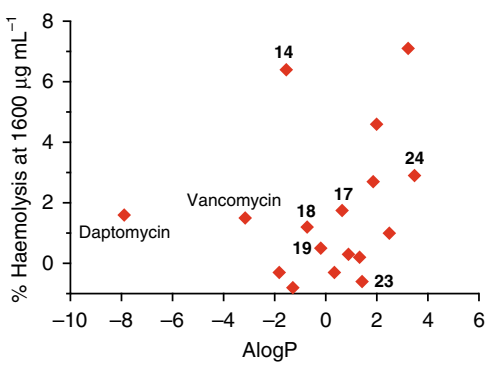

d

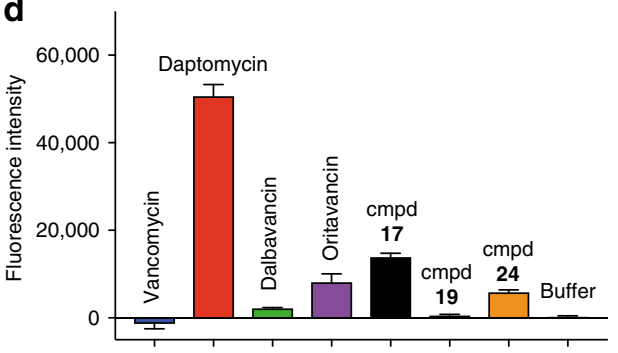

Fig. 7 Membrane effects. a SPR binding of vancomycin, $\mathbf{1 7}$ and $\mathbf{2 4}$ to L1 chips coated with lipid bilayers formed from DMPC or DMPG (errors are mean \pm S. $\mathrm{D}, n=3) . \mathbf{b} \%$ haemolysis of human red blood cells in whole blood induced by a set of derivatives at $1600 \mu \mathrm{g} \mathrm{mL} \mathrm{L}^{-1}$ relative to complete lysis, compared with their calculated lipophilicity $(n=2)$. c Membrane depolarisation: change in fluorescence intensity of the reporter dye diSC3(5) over 30 min following treatment of S. aureus ATCC 43300 (early exponential phase) with test compounds at $16 \mu \mathrm{mL}^{-1}$ (errors are mean \pm S.D, $n=4$ ). d Membrane permeabilisation: maximal fluorescence intensity of the reporter dye propidium iodide after $2 \mathrm{~h}$ following incubation of $\mathrm{S}$. aureus ATCC 43300 (early exponential phase) with test compounds $\left(16 \mu \mathrm{gL} \mathrm{m}^{-1}\right)$ for $1 \mathrm{~h}$ at $37^{\circ} \mathrm{C}$ (errors are mean \pm S.D, $n=4$ )

Converting the linker from a disulphide bridge to a carbon-based chain substantially improved the drug-like properties of the constructs, restoring plasma stability. Selected candidates demonstrated excellent in vivo activity in multiple murine models of infection at doses up to 40-fold lower than vancomycin (Fig. 5), with a pharmacokinetic (PK) profile consistent with once daily dosing in humans (Fig. 4). Induced resistance experiments demonstrated that the compounds retained a low propensity to cause resistance, in contrast to daptomycin (Fig. 3).

The remarkably potent activity possessed by these antibiotics is most likely due to a membrane anchoring chelate effect that enhances antibiotic binding to cell wall precursors at the cell surface. In effect, intra-molecular binding is achieved as both the antibiotic and its target are attached via membrane anchors to the same template. Examining peptidoglycan synthesis in a cell-free system demonstrated that the vancapticins caused greater inhibition of biosynthetic activity than vancomycin, corresponding with much greater quantities of Ac-Lys(Ac)-D-Ala-D-Ala ligand in free solution required to antagonise vancapticin antimicrobial activity against live bacteria (Fig. 6).

The enhanced ability to inhibit peptidoglycan synthesis is accompanied by membrane binding and disruption (Fig. 7). SPR studies demonstrated a greater propensity for binding to an anionic lipid bilayer compared to vancomycin. A diSC3(5) dyebased assay in live bacteria showed that vancapticins induced membrane depolarisation to a similar extent to that seen with oritavancin, with minimal activity observed with vancomycin or dalbavancin. In contrast, a membrane permeabilisation assay (propidium iodide dye) gave variable results for the same vancapticins, with 17 and 24 eliciting a comparable response as oritavancin, but fourfold to sixfold less than daptomycin. Vancapticin 19 and dalbavancin were much less active, while vancomycin had no effect. The increased membrane activity of the vancapticins appears to enhance their potency, but does not translate into increased killing kinetics: compound 24 shared a similar slowly bactericidal profile with vancomycin (Fig. 2).

In summary, we report the design and development of promising new semisynthetic lipoglycopeptides intended to selectively interact with bacterial membranes. Further improvements and additional studies are ongoing to assess the potential to advance the vancapticins as a new clinical candidate for the treatment of drug-resistant Gram-positive infections.

\section{Methods}

Ethics approvals. Research was conducted under an Institutional Animal Care and Use Committee approved protocol in compliance with the Animal Welfare Act, PHS Policy and other federal statutes and regulations relating to animals and experiments involving animals. Contract facilities where animal studies were conducted were accredited by the Association for Assessment and Accreditation of Laboratory Animal Care, International and adhere to principles stated in the Guide for the Care and Use of Laboratory Animals, National Research Council, 2011. Studies performed at the University of Queensland were approved by the Molecular Biosciences Animal Ethics Committee. Sample size for in vivo studies was selected based on minimising animal use while providing sufficient data points to show significant differences based on historical studies. No animals were excluded from analysis. No documented method of randomisation was employed, with animals randomly assigned to groups. Code numbers were employed for all in vivo studies, so the study investigator was blinded to the actual identity of compounds. Human ethics approval from the University of Queensland Medical Research Ethics Committee was obtained for use of human blood for haemolysis studies.

Chemical synthesis. General: C-terminal amide or methyl amide containing peptides were assembled on Fmoc-Rink Amide AM polystyrene resin (Iris Biotech $\mathrm{GmbH}$ ) or HypoGel hydroxymethylbenzoic acid (HMBA) resin (Iris Biotech $\mathrm{GmbH})$, respectively. Peptides bearing free C-terminal carboxylic acids were assembled on Fmoc-Cys(Trt) or Fmoc-Lys(Boc) Wang polystyrene resin. 9Fluorenylmethyloxycarbonyl (Fmoc)-L-amino acids utilised standard side-chain protecting groups: tert-Butyl (Asp, Ser), Trityl (Cys), tert-Butoxycarbony (Boc) or 4-methyltrityl (Mtt) or 1-(4,4-dimethyl-2,6-dioxocyclohexylidene)-3-methylbutyl (ivDde) (Lys, Dab, Dap, Orn) and were purchased from Iris Biotech $\mathrm{GmbH}$, as were the coupling reagents $O$-(benzotriazol-1-yl)- $N, N, N^{\prime}, N^{\prime}$-tetramethyluronium hexafluorophosphate (HBTU) and $O$-(benzotriazol-1-yloxy)tripyrrolidinophosphonium hexafluorophosphate (PyBop). Azabenzotriazol-1-yl- $N, N, N^{\prime}, N^{\prime}-$ 
tetramethyluronium hexafluorophosphate (HATU) was sourced from GenScript Corporation (USA), and (S)-pyridylthio cysteamine.HCl from Toronto Research Chemicals Inc. Vancomycin.HCl 1 was purchased from Hallochem Pharma Co. Ltd, daptomycin 4 from Molekula (Cat \# 64342447) and oritavancin diphosphate 5 (Cat \# 317101), and dalbavancin.HCl 3 (Cat \# 317136) from MedKoo Biosciences. Dalbavancin 3 was also synthesised internally, as was telavancin 2 . Analytical liquid chromatography / mass spectrometry (LC/MS) was performed using reverse-phase high-performance liquid chromatograph (RP-HPLC) on an Eclipse XDB-Phenyl column $\left(5 \mu \mathrm{m}, 4.6 \times 150 \mathrm{~mm}, 1 \mathrm{~mL} \mathrm{~min}^{-1}\right)$ coupled to an Agilent 1200 series system with detection by a single quadrupole mass spectrometer (6110), a UV detector operating at $210 \mathrm{~nm}$ and an evaporative light scattering detector (ELSD). Preparative HPLC was performed using reverse-phase HPLC on an Eclipse XDBPhenyl column $\left(5 \mu \mathrm{m}, 21.2 \times 100 \mathrm{~mm}, 20 \mathrm{~mL} \mathrm{~min}^{-1}\right)$ coupled to an Agilent 1260 Infinity system with detection by UV $(210 \mathrm{~nm})$. Elution was effected using appropriate gradients with $0.05 \%$ formic acid (analytical) or $0.1 \%$ trifluoroacetic acid (TFA) (preparative) in water (solvent A) and $0.05 \%$ formic acid (analytical) or $0.1 \%$ TFA (preparative) in acetonitrile (solvent B). (+)-electrospray ionisation mass spectrometry/mass spectrometry (ESI-MS/MS) were obtained using an API QSTAR $^{\text {TM }}$ Pulsar Hybrid LC-MS/MS System using the following conditions: column oven $40^{\circ} \mathrm{C}$, MS parameters: CUR: 20 , IS: 5300 , TEM: 450, GS1: 45, GS2: 45 , ihe: ON, DP 60. HPLC Column: Waters Atlantis ${ }^{\circledR}$ T3 $5 \mu \mathrm{m} 2.1 \times 50 \mathrm{~mm}$ with Atlantis ${ }^{\Phi}$ T3 $5 \mu \mathrm{m} 2.1 \times 10 \mathrm{~mm}$ guard column. Flow rates and solvent: $0.4 \mathrm{~mL} \mathrm{~min}$ ${ }^{-1}$, solvent $\mathrm{A}: 0.1 \%$ formic acid in $\mathrm{H}_{2} \mathrm{O}$, solvent $\mathrm{B}: 0.1 \%$ formic acid in acetonitrile; isocratic $0 \%$ B from $0 \rightarrow 1 \mathrm{~min}$, gradient $0 \% \rightarrow 100 \%$ B from $2 \rightarrow 9 \mathrm{~min}$, isocratic $100 \%$ from $5 \rightarrow 12$ min, gradient $100 \% \rightarrow 0 \%$ B from $12 \rightarrow 12.5$ min and isocratic $2 \%$ B from $12.5 \rightarrow 17.5 \mathrm{~min}$. High resolution mass spectrometry (HRMS) was performed on a Bruker Micro time-of-flight (TOF) mass spectrometer using (+)-ESI calibrated to $\mathrm{NH}_{4} \mathrm{OAc} .{ }^{1} \mathrm{H}(600 \mathrm{MHz}),{ }^{13} \mathrm{C}(150 \mathrm{MHz})$ and $2 \mathrm{D}$ NMR spectra were obtained in $\mathrm{d}_{6}$-dimethylsulphoxide (DMSO) calibrated to TMS resonances $\left(\delta_{\mathrm{H}} 0.00, \delta_{\mathrm{C}} 0.0\right)$ using a Bruker Avance-600 spectrometer equipped with a TXI cryoprobe.

\section{General procedure A: Loading of Fmoc-L-Lys(ivDde)-OH or Fmoc-L-Orn} (ivDde)-OH onto hypogel HMBA resin. HypoGel HMBA resin was washed with anhydrous dimethylformamide (DMF) (3x) under an inert atmosphere. A mixture of Fmoc-L-Lys(ivDde)-OH or Fmoc-L-Orn(ivDde)-OH (5 eq), hydro-

xybenzotriazole (5 eq) in anhydrous DMF $(2.5 \mathrm{~mL}$ per $1 \mathrm{mmol}$ amino acid) was treated with 1,3-diisopropylcarbodiimide (DIC) (5 eq) and 4-

dimethylaminopyridine $(0.3 \mathrm{eq})$. The resulting solution was added to the resin and the resin was shaken at room temperature overnight. The resin was drained, and successively washed with DMF, methanol $(\mathrm{MeOH})$ and dichloromethane (DCM) $(3 \times$ each). A solution of acetic anhydride $(4 \mathrm{eq})$ and diisopropylethylamine (DIPEA) (8 eq) in DMF ( $\sim 10 \mathrm{~mL}$ per 1 gram of resin) was added to the resin to block any unreacted sites. After shaking for $1 \mathrm{~h}$, the resin was drained and washed with DMF, MeOH and DCM ( $3 \times$ each) and dried in vacuo.

\section{General procedure B: Standard Fmoc solid phase peptide synthesis. The} starting resin was washed with anhydrous DMF $(3 \times)$. Fmoc-deprotection was performed by shaking the resin with piperidine in DMF $(20: 80 \mathrm{v} / \mathrm{v}, 10 \mathrm{~mL}$ per $1 \mathrm{~g}$ of resin) for $30 \mathrm{~min}$. The resin was drained and washed successively with DMF, $\mathrm{MeOH}, \mathrm{DCM}$ and DMF $(3 \times$ each). A solution of Fmoc-protected amino acid or fatty acid (4 equiv) in DMF ( 0.4 M) was treated with HBTU (4 equiv) and DIPEA (16 equiv). After $10 \mathrm{~min}$, the activated amino acid solution was added to the resin. The resin was agitated at room temperature (RT) for $1 \mathrm{~h}$, drained, washed successively with DMF, $\mathrm{MeOH}$ and DCM $(3 \times$ each), and dried in vacuo. Coupling efficiency was assessed using the Kaiser test and/or by cleavage of 2-3 mg of resin and analysis by LCMS. If required, the coupling reaction was repeated.

General procedure C: Removal of the ivDde protecting group. Crude lipopeptide was treated with an excess of hydrazine hydrate ( $2 \% \mathrm{v} / \mathrm{v}$ in DMF, ca. $10 \mathrm{eq})$ at RT. Reaction progress was monitored by LC/MS. Upon completion, the solution was concentrated in vacuo and the resulting crude product was lyophilised (ACN/ $\mathrm{H}_{2} \mathrm{O}$ ). The material was then used in the next step without further purification (intermediate) or purified by preparative HPLC (final product).

General procedure D: Removal of the 4-methyltrityl (Mtt) group. The Mttprotected vancomycin derivative was treated with a solution of TFA/triethylsilane (TES)/DCM (2:5:93, $40 \mathrm{~mL}$ per $1 \mathrm{~g}$ of crude peptide) at room temperature for $1 \mathrm{~h}$ and concentrated under reduced pressure. The process was repeated if deprotection was incomplete as determined by LCMS analysis. Upon completion, the solution was concentrated in vacuo and the crude product was purified by preparative HPLC.

General procedure E: Resin cleavage. (i) Rink-amide, Wang- and 2-CTC-resins. Peptides incorporating cysteine were cleaved from the resin by agitation with TFA/ 1,2-ethanedithiol (EDT)/triisopropylsilane (TIPS)/water (90/5/2.5/2.5 v/v/v/v, 20 $\mathrm{mL}$ per $1 \mathrm{~g}$ of resin). Non-cysteine containing peptides were cleaved from the resin by agitation with TFA/TIPS/water (95:2.5:2.5 v/v/v, $20 \mathrm{~mL}$ per $1 \mathrm{~g}$ of resin). Resins were filtered and washed with TFA ( $3 \times)$. The combined filtrates were concentrated in vacuo and the crude peptides were precipitated with cold diethyl ether, isolated by centrifugation and lyophilised $\left(\mathrm{ACN} / \mathrm{H}_{2} \mathrm{O}\right)$. (ii) $\mathrm{HMBA}$ hypogel resin: Cterminal N-methyl amides. Prior to cleavage, the resin was washed with tetrahydrofuran (THF) $(3 \times)$ and DIPEA $(2 \times)$ and then treated with methylamine $(2 \mathrm{M}$ in THF, $20 \mathrm{~mL}$ per $1 \mathrm{~g}$ of resin) with overnight agitation at RT. The resin was drained, and washed with THF, DCM and ACN ( $3 \times$ each). The combined filtrates were removed under reduced pressure to afford crude product.

eneral procedure F: Disulphide exchange. GPeptides incorporating cysteine were dissolved in acetonitrile/water (1:1, ca. $150 \mathrm{~mL}$ per $1 \mathrm{mmol}$ of substrate), and the $\mathrm{pH}$ was adjusted ( $\mathrm{pH} 8-9$ ) by addition of DIPEA (ca. 5 eq). A solution of 43 (1.5 equiv) in acetonitrile/water (1:1, ca. $100 \mathrm{~mL}$ per $1 \mathrm{mmol}$ of 43 ) was added. After standing at room temperature for $1 \mathrm{~h}$, the reaction mixture was concentrated by lyophilisation, and the resulting crude product was purified by preparative RPHPLC.

General procedure G: Solution phase coupling with vancomycin. A stirred solution of peptide (1 eq), $O$-(7-Azabenzotriazol-1-yl)- $N, N, N^{\prime}, N^{\prime}$-tetramethyluronium hexafluorophosphate (HATU) $(1.3 \mathrm{eq})$ and vancomycin hydrochloride (1.2 eq) in anhydrous DMF ( $\sim 30 \mathrm{~mL}$ per $1 \mathrm{mmol}$ of peptide) was cooled to $0^{\circ} \mathrm{C}$. After $30 \mathrm{~min}$, DIPEA was added $(10 \mathrm{eq})$, and stirring was continued for $1 \mathrm{~h}$ at room temperature. The solvent was evaporated in vacuo and the residue was lyophilised from $\mathrm{ACN} / \mathrm{H}_{2} \mathrm{O}$. The crude product was purified by preparative RPHPLC.

Structure elucidation of synthesised compounds. Compound purity was determined using LC- $(+)$-ESI-MS/UV/ELSD and their molecular formulae determined by (+)-HR-ESI-MS. (+)-ESI-TOF-MS/MS analysis was also undertaken and representative examples of fragmentation are given in Supplementary Fig. 10. The major MS/MS fragment of all compounds was $m / z 144$, which corresponded to the loss of the vancosamine. This and other fragments showed that the two sugars, vancosamine and glucose, remained intact throughout the reaction sequence. Sequential losses of the MIE and EEPS fragments could also be observed in the MS MS spectra. ${ }^{1} \mathrm{H},{ }^{13} \mathrm{C}$ and $2 \mathrm{D}$ (COSY, TOCSY, HSQC, HMBC and HSQC-TOCSY) NMR experiments were used to confirm the structure of 19 (Supplementary Table 1).

Synthesis of 2-[(2-Pyridinyl)dithio]ethanamino-vancomycin (43): To a solution of vancomycin hydrochloride $\mathbf{1}(6.89 \mathrm{~g}, 4.64 \mathrm{mmol}, 1.2$ equiv) in dry dimethylsulphoxide (DMSO) $(68 \mathrm{~mL}, 69 \mathrm{mM})$ was added a solution of (S)-pyridylthio cysteamine hydrochloride (PDEA, $998 \mathrm{mg}, 3.87 \mathrm{mmol}$ ) in dry DMF $(68 \mathrm{~mL}, 56.9$ $\mathrm{mM})$. PyBOP (2.82 g, $5.42 \mathrm{mmol}$, 1.4 equiv) in dry DMF $(10.8 \mathrm{~mL}, 0.5 \mathrm{M})$ was added followed by DIPEA $(3.37 \mathrm{~mL}, 19.3 \mathrm{mmol}, 5$ equiv). The resulting solution was stirred at room temperature overnight and the solvent was removed under reduced pressure. The crude product was precipitated with diethyl ether and collected by vacuum filtration as a white solid, $10.8 \mathrm{~g}$. The crude product was used for the disulphide exchange reaction without further purification. A small amount of crude product (100 mg) was purified by HPLC to give $\mathbf{4 3}$ as white solid (TFA salt) $47 \mathrm{mg}, 71 \%$ yield. HPLC purity $>95 \%, t_{\mathrm{R}} 6.4$. (ES) $\mathrm{m} / z\left(\mathrm{MH}_{2}{ }^{2+}\right) 808.7,\left(\mathrm{MH}_{3}{ }^{3+}\right)$ 540.0. HRMS exact mass (ESI microTOF-LC): calcd for $\mathrm{C}_{73} \mathrm{H}_{85} \mathrm{Cl}_{2} \mathrm{~N}_{11} \mathrm{O}_{23} \mathrm{~S}_{2}$ $808.7314\left(\mathrm{MH}_{2}^{2+}\right)$, found 808.7348 .

nC9CO-GSSKSPSKKKKKKPGDC( $\left.\mathrm{SCH}_{\mathbf{2}} \mathrm{CH}_{\mathbf{2}} \mathbf{N H}-V a n c o m y c i n\right)-\mathrm{NH}_{\mathbf{2}}$ (6): HPLC purity $>95 \%, t_{\mathrm{R}} 4.8$. (ES) $\mathrm{m} / z\left(\mathrm{MH}_{3}{ }^{3+}\right) 1150.3,\left(\mathrm{MH}_{4}{ }^{4+}\right) 863.0\left(\mathrm{MH}_{5}{ }^{5+}\right) 690.7$, $\left(\mathrm{MH}_{6}^{6+}\right)$ 575.8, $\left(\mathrm{MH}_{7}{ }^{7+}\right)$ 493.7.

nC11CO-GSSKSPSKKKKKKPGDC( $\mathrm{SCH}_{2} \mathrm{CH}_{2} \mathrm{NH}$-Vancomycin)- $\mathrm{NH}_{2}$ (7): HPLC purity $>95 \%, t_{\mathrm{R}} 5.0$. (ES) $\mathrm{m} / z\left(\mathrm{MH}_{3}{ }^{3+}\right) 1159.4,\left(\mathrm{MH}_{4}{ }^{4+}\right) 870.2\left(\mathrm{MH}_{5}{ }^{5+}\right)$ 696.3, $\left(\mathrm{MH}_{6}{ }^{6+}\right)$ 580.5, $\left(\mathrm{MH}_{7}{ }^{7+}\right)$ 497.6. HRMS exact mass (ESI microTOF-LC): calcd for $\mathrm{C}_{155} \mathrm{H}_{241} \mathrm{Cl}_{2} \mathrm{~N}_{35} \mathrm{O}_{47} \mathrm{~S}_{2}{ }^{4+} 869.6585\left(\mathrm{MH}_{4}{ }^{4+}\right)$, found 869.6595 .

Myristoyl-GSSKSPSKKKKKKPGDC-NH $\mathbf{N}_{\mathbf{2}}(\mathbf{8 a})$ : HPLC purity $>95 \%, t_{\mathrm{R}} 5.5$ (ES) $m / z\left(\mathrm{MH}_{2}{ }^{2+}\right)$ 1000.0, $[\mathrm{M}+3 \mathrm{H}]^{3+}$ 667.2, $[\mathrm{M}+4 \mathrm{H}]^{4+} 500.7,[\mathrm{M}+5 \mathrm{H}]^{5+} 400.8$, HRMS exact mass (ESI microTOF-LC): calcd for $\mathrm{C}_{89} \mathrm{H}_{167} \mathrm{~N}_{25} \mathrm{O}_{24} \mathrm{~S}^{4+} 500.5579$ $\left(\mathrm{MH}_{4}^{4+}\right)$, found 500.5645 .

nC13CO-GSSKSPSKKKKKKPGDC( $\mathrm{SCH}_{2} \mathrm{CH}_{2} \mathrm{NH}$-Vancomycin)- $\mathrm{NH}_{2}$ (8): HPLC purity $>95 \%, t_{\mathrm{R}} 5.0$. (ES) $\mathrm{m} / z\left(\mathrm{MH}_{3}{ }^{3+}\right) 1168.9,\left(\mathrm{MH}_{4}{ }^{4+}\right) 877.2\left(\mathrm{MH}_{5}{ }^{5+}\right)$ 702.0, $\left(\mathrm{MH}_{6}{ }^{6+}\right)$ 585.2, $\left(\mathrm{MH}_{7}{ }^{7+}\right)$ 501.7. HRMS exact mass (ESI microTOF-LC): calcd for $\mathrm{C}_{157} \mathrm{H}_{248} \mathrm{Cl}_{2} \mathrm{~N}_{35} \mathrm{O}_{47} \mathrm{~S}_{2}{ }^{7+} 501.3839\left(\mathrm{MH}_{7}{ }^{7+}\right)$, found 501.3819.

nC15CO-GSSKSPSKKKKKKPGDC( $\mathrm{SCH}_{2} \mathrm{CH}_{2} \mathrm{NH}$-Vancomycin)- $\mathrm{NH}_{2}$ (9): HPLC purity $>95 \%, t_{\mathrm{R}} 5.3$. (ES) $\mathrm{m} / z\left(\mathrm{MH}_{3}{ }^{3+}\right) 1178.2,\left(\mathrm{MH}_{4}{ }^{4+}\right) 884.1\left(\mathrm{MH}_{5}{ }^{5+}\right)$ 707.5, $\left(\mathrm{MH}_{6}{ }^{6+}\right)$ 589.8, $\left(\mathrm{MH}_{7}{ }^{7+}\right)$ 505.7. HRMS exact mass (ESI microTOF-LC): calcd for $\mathrm{C}_{159} \mathrm{H}_{252} \mathrm{Cl}_{2} \mathrm{~N}_{35} \mathrm{O}_{47} \mathrm{~S}_{2}{ }^{++} 505.3884\left(\mathrm{MH}_{7}{ }^{7+}\right)$, found 505.3859 .

4-Ph-Bz-GSSKSPSKKKKKKPGDC( $\mathrm{SCH}_{2} \mathrm{CH}_{2} \mathrm{NH}$-Vancomycin)- $\mathrm{NH}_{2}$ (10): HPLC purity $>95 \%, t_{\mathrm{R}} 4.8$. (ES) $\mathrm{m} / z\left(\mathrm{MH}_{3}{ }^{3+}\right)$ 1159.2, $\left(\mathrm{MH}_{4}{ }^{4+}\right)$ 869.6, $\left(\mathrm{MH}_{5}{ }^{5+}\right)$ 695.8, $\left(\mathrm{MH}_{6}{ }^{6+}\right)$ 580.1, $\left(\mathrm{MH}_{7}{ }^{7+}\right)$ 497.3.

nC13CO-GSSKSPSKKKPGDC( $\mathrm{SCH}_{2} \mathrm{CH}_{2} \mathrm{NH}$-Vancomycin)- $\mathrm{NH}_{2}$ (11): HPLC purity $>95 \%, t_{\mathrm{R}} 6.1$. (ES) $\mathrm{m} / z\left(\mathrm{MH}_{3}{ }^{3+}\right) 1040.8,\left(\mathrm{MH}_{4}{ }^{4+}\right) 781.0\left(\mathrm{MH}_{5}{ }^{5+}\right)$ 625.0, $\left(\mathrm{MH}_{6}{ }^{6+}\right)$ 521.0. HRMS exact mass (ESI microTOF-LC): calcd for $\mathrm{C}_{139} \mathrm{H}_{211} \mathrm{Cl}_{2} \mathrm{~N}_{29} \mathrm{O}_{44} \mathrm{~S}_{2}{ }^{6+} 520.7325\left(\mathrm{MH}_{6}{ }^{6+}\right)$, found 520.7328 . 
Myristoyl-GSSKSPSKKKPC-NH 2 (12a): HPLC purity $>95 \%, t_{\mathrm{R}}$ 5.7. (ES) $\mathrm{m} / z$ $\left(\mathrm{MH}_{2}{ }^{2+}\right)$ 721.9, $[\mathrm{M}+3 \mathrm{H}]^{3+}$ 481.7, $[\mathrm{M}+4 \mathrm{H}]^{4+}$ 361.5. HRMS exact mass (ESI microTOF-LC): calcd for $\mathrm{C}_{65} \mathrm{H}_{121} \mathrm{~N}_{17} \mathrm{O}_{17} \mathrm{~S}^{2+} 721.9418\left(\mathrm{MH}_{2}^{2+}\right)$, found 721.9427

nC13CO-GSSKSPSKKKPC( $\mathrm{SCH}_{2} \mathrm{CH}_{2} \mathrm{NH}$-Vancomycin)- $\mathrm{NH}_{2}$ (12): HPLC purity $>95 \%, t_{\mathrm{R}} 5.2$. (ES) $\mathrm{m} / z\left(\mathrm{MH}_{2}{ }^{2+}\right) 1474.1,\left(\mathrm{MH}_{3}{ }^{3+}\right)$ 983.6, $\left(\mathrm{MH}_{4}{ }^{4+}\right) 738.0$ $\left(\mathrm{MH}_{5}{ }^{5+}\right)$ 590.2, $\left(\mathrm{MH}_{6}{ }^{6+}\right)$ 492.4. HRMS exact mass (ESI microTOF-LC): calcd for $\mathrm{C}_{133} \mathrm{H}_{202} \mathrm{Cl}_{2} \mathrm{~N}_{27} \mathrm{O}_{40} \mathrm{~S}_{2}{ }^{5+} 590.2679\left(\mathrm{MH}_{5}{ }^{5+}\right)$, found 590.2701 .

Myristoyl-GSKKKC-NH ${ }_{2}$ (13a): HPLC purity $>95 \%, t_{\mathrm{R}} 6.1$. (ES) $\mathrm{m} / z\left(\mathrm{MH}^{+}\right)$ 859.4, $\left(\mathrm{MH}_{2}{ }^{2+}\right) 430.3,[\mathrm{M}+3 \mathrm{H}]^{3+}$ 287.3. HRMS exact mass (ESI microTOF-LC): calcd for $\mathrm{C}_{40} \mathrm{H}_{80} \mathrm{~N}_{10} \mathrm{O}_{8} \mathrm{~S}^{2+} 430.2935\left(\mathrm{MH}_{2}{ }^{2+}\right)$, found 430.3061 .

nC13CO-GSKKKC( $\mathrm{SCH}_{2} \mathrm{CH}_{2} \mathrm{NH}$-Vancomycin)- $\mathrm{NH}_{2}$ (13): HPLC purity > 95\%, $t_{\mathrm{R}}$ 5.8. (ES) $\mathrm{m} / z\left(\mathrm{MH}_{2}{ }^{2+}\right)$ 1182.4, $\left(\mathrm{MH}_{3}{ }^{3+}\right)$ 789.0, $\left(\mathrm{MH}_{4}{ }^{4+}\right) 592.1\left(\mathrm{MH}_{5}{ }^{5+}\right)$ 473.9. HRMS exact mass (ESI microTOF-LC): calcd for $\mathrm{C}_{108} \mathrm{H}_{160} \mathrm{Cl}_{2} \mathrm{~N}_{20} \mathrm{O}_{31} \mathrm{~S}_{2}{ }^{4+}$ $591.7589\left(\mathrm{MH}_{4}{ }^{4+}\right)$, found 591.7585 .

Myristoyl-GSKKKC-OH (14a): HPLC purity $>95 \%, t_{\mathrm{R}} 6.3$. (ES) $\mathrm{m} / z\left(\mathrm{MH}^{+}\right)$ 860.4, $\left(\mathrm{MH}_{2}{ }^{2+}\right) 430.8,\left(\mathrm{MH}_{3}{ }^{3+}\right)$ 287.6. HRMS exact mass (ESI microTOF-LC): calcd for $\mathrm{C}_{40} \mathrm{H}_{78} \mathrm{~N}_{9} \mathrm{O}_{9} \mathrm{~S}^{+} 860.5638$, found 860.5802 .

nC13CO-GSKKKC( $\mathrm{SCH}_{2} \mathrm{CH}_{2} \mathrm{NH}$-Vancomycin)-OH (14): HPLC purity > 95\%, $t_{\mathrm{R}}$ 5.9. (ES) $\mathrm{m} / z\left(\mathrm{MH}_{2}{ }^{2+}\right)$ 1184.7, $\left(\mathrm{MH}_{3}{ }^{3+}\right)$ 789.7, $\left(\mathrm{MH}_{4}{ }^{4+}\right) 592.4\left(\mathrm{MH}_{5}{ }^{5+}\right)$ 474.1. HRMS exact mass (ESI microTOF-LC): calcd for $\mathrm{C}_{108} \mathrm{H}_{158} \mathrm{Cl}_{2} \mathrm{~N}_{19} \mathrm{O}_{32} \mathrm{~S}_{2}{ }^{4+}$ $789.0041\left(\mathrm{MH}_{4}{ }^{4+}\right)$, found 789.0006 .

Myristoyl-KKKC-OH - disulphide dimer (15a): HPLC purity $>95 \%, t_{\mathrm{R}} 6.4$ (ES) $\mathrm{m} / z\left(\mathrm{MH}^{+}\right)$1429.8, $\left(\mathrm{MH}_{2}{ }^{2+}\right)$ 715.5, $\left(\mathrm{MH}_{3}{ }^{3+}\right)$ 477.4, $\left(\mathrm{MH}_{4}{ }^{4+}\right)$ 358.4 $\left(\mathrm{MH}_{5}{ }^{5+}\right)$ 286.9. HRMS exact mass (ESI microTOF-LC): calcd for $\mathrm{C}_{70} \mathrm{H}_{138} \mathrm{~N}_{14} \mathrm{O}_{12} \mathrm{~S}_{2}{ }^{2+}$ 715.5025, found 715.5058 .

nC13CO-KKKC( $\mathrm{SCH}_{2} \mathrm{CH}_{2} \mathbf{N H}$-Vancomycin)-OH (15): HPLC purity $>95 \%$, $t_{\mathrm{R}}$ 5.8. (ES) $\mathrm{m} / z\left(\mathrm{MH}_{2}{ }^{2+}\right) 1110.8,\left(\mathrm{MH}_{3}{ }^{3+}\right) 741.5,\left(\mathrm{MH}_{4}{ }^{4+}\right) 556.4\left(\mathrm{MH}_{5}{ }^{5+}\right) 445.4$ HRMS exact mass (ESI microTOF-LC): calcd for $\mathrm{C}_{103} \mathrm{H}_{149} \mathrm{Cl}_{2} \mathrm{~N}_{17} \mathrm{O}_{29} \mathrm{~S}_{2}{ }^{2+}$ $1110.9757\left(\mathrm{MH}_{2}{ }^{2+}\right)$, found 1110.9783 .

nC13CO-GSKKK-K(Vancomycin)-OH (16): HPLC purity $>95 \%, \mathbf{t}_{\mathrm{R}}$ 6.1. (ES) $\mathrm{m} / z\left(\mathrm{MH}_{3}{ }^{3+}\right) 772.9,\left(\mathrm{MH}_{4}{ }^{4+}\right)$ 579.8, $\left(\mathrm{MH}_{5}{ }^{5+}\right)$ 464.1. HRMS exact mass (ESI microTOF-LC): calcd for $\mathrm{C}_{109} \mathrm{H}_{159} \mathrm{Cl}_{2} \mathrm{~N}_{19} \mathrm{O}_{2}{ }^{2+} 1158.0382\left(\mathrm{MH}_{2}{ }^{2+}\right)$, found 1158.0396 .

nC13CO-KKK-K(Vancomycin)-OH (17): HPLC purity $>95 \%, t_{\mathrm{R}} 5.9$. (ES) $\mathrm{m} / z$ $1086.9\left(\mathrm{MH}_{2}{ }^{2+}\right),\left(\mathrm{MH}_{3}{ }^{3+}\right) 724.8,\left(\mathrm{MH}_{4}{ }^{4+}\right)$ 543.8. HRMS exact mass (ESI microTOF-LC): calcd for $\mathrm{C}_{104} \mathrm{H}_{153} \mathrm{Cl}_{2} \mathrm{~N}_{17} \mathrm{O}_{29}{ }^{4+} 543.5094\left(\mathrm{MH}_{4}{ }^{4+}\right)$, found 543.5109 .

nC10CO-KKK-K(Vancomycin)-OH (18): HPLC purity $>95 \%, t_{\mathrm{R}}$ 5.5. (ES) $\mathrm{m} / z$ $\left(\mathrm{MH}_{2}{ }^{2+}\right)$ 1065.8, $\left(\mathrm{MH}_{3}{ }^{3+}\right)$ 710.7, $\left(\mathrm{MH}_{4}{ }^{4+}\right)$ 533.4. HRMS exact mass (ESI microTOF-LC): calcd for $\mathrm{C}_{101} \mathrm{H}_{146} \mathrm{Cl}_{2} \mathrm{~N}_{17} \mathrm{O}_{29}{ }^{3+} 710.3278\left(\mathrm{MH}_{3}{ }^{3+}\right)$, found 710.3245 .

nC10CO-KK-K(Vancomycin)-OH (19): HPLC purity $>95 \%, t_{\mathrm{R}}$ 4.5. (ES) $\mathrm{m} / z$ $\left(\mathrm{MH}_{2}{ }^{2+}\right)$ 1001.9, $\left(\mathrm{MH}_{3}{ }^{3+}\right)$ 668.4, $\left(\mathrm{MH}_{4}{ }^{4+}\right)$ 501.3. HRMS exact mass (ESI microTOF-LC): calcd for $\mathrm{C}_{95} \mathrm{H}_{135} \mathrm{Cl}_{2} \mathrm{~N}_{15} \mathrm{O}_{28}{ }^{4+} 500.9739\left(\mathrm{MH}_{4}{ }^{4+}\right)$, found 500.9753 .

nC10CO-K(Vancomycin)-OH (20): HPLC purity $>95 \%$, $t_{\mathrm{R}}$ 7.1. (ES) $\mathrm{m} / \mathrm{z}$ $\left(\mathrm{MH}_{2}{ }^{2+}\right)$ 873.5, $\left(\mathrm{MH}_{3}{ }^{3+}\right)$ 582.9. HRMS exact mass (ESI microTOF-LC):

$\mathrm{C}_{83} \mathrm{H}_{110} \mathrm{Cl}_{2} \mathrm{~N}_{11} \mathrm{O}_{26}{ }^{3+} 582.2328\left(\mathrm{MH}_{3}{ }^{3+}\right)$, found 582.2322 .

nC10CO-KK-K(Vancomycin)-NH2 (21): HPLC purity $>95 \%, t_{\mathrm{R}}$ 5.4. (ES) $\mathrm{m} / z$ $\left(\mathrm{MH}_{2}{ }^{2+}\right)$ 1000.3, $\left(\mathrm{MH}_{3}{ }^{3+}\right)$ 667.8, $\left(\mathrm{MH}_{4}{ }^{4+}\right)$ 501.0. HRMS exact mass (ESI microTOF-LC): calcd for $\mathrm{C}_{95} \mathrm{H}_{136} \mathrm{Cl}_{2} \mathrm{~N}_{16} \mathrm{O}_{27}{ }^{4+} 500.7279\left(\mathrm{MH}_{4}{ }^{4+}\right)$, found 500.7270 .

nC10CO-KK-K(Vancomycin)-NHMe (22): HPLC purity $>95 \%$, $t_{\mathrm{R}}$ 5.6. (ES) $m / z\left(\mathrm{MH}_{2}{ }^{2+}\right)$ 1007.8, $\left(\mathrm{MH}_{3}{ }^{3+}\right)$ 672.3, $\left(\mathrm{MH}_{4}{ }^{4+}\right)$ 504.5. HRMS exact mass (ESI microTOF-LC): calcd for $\mathrm{C}_{96} \mathrm{H}_{138} \mathrm{Cl}_{2} \mathrm{~N}_{16} \mathrm{O}_{27}{ }^{4+} 504.2318\left(\mathrm{MH}_{4}{ }^{4+}\right)$, found 504.2315 .

POP2K-KK-K(Vancomycin)-OH (23): HPLC purity $>95 \%, t_{\mathrm{R}}$ 6.7. (ES) $\mathrm{m} / \mathrm{z}$ $\left(\mathrm{MH}_{2}{ }^{2+}\right)$ 1177.3, $\left(\mathrm{MH}_{3}{ }^{3+}\right)$ 785.3, $\left(\mathrm{MH}_{4}{ }^{4+}\right)$ 589.4. HRMS exact mass (ESI microTOF-LC): calcd for $\mathrm{C}_{116} \mathrm{H}_{141} \mathrm{Cl}_{2} \mathrm{~N}_{17} \mathrm{O}_{32}{ }^{3+} 1176.9647\left(\mathrm{MH}_{3}{ }^{3+}\right)$, found 1176.9644 .

POB2K-KK-K(Vancomycin)-NHMe (24): HPLC purity $>95 \%, t_{\mathrm{R}} 6.1$. (ES) $\mathrm{m} /$ $z\left(\mathrm{MH}_{2}{ }^{2+}\right)$ 1185.2, $\left(\mathrm{MH}_{3}{ }^{3+}\right)$ 789.9, $\left(\mathrm{MH}_{4}{ }^{4+}\right)$ 592.6. HRMS exact mass (ESI microTOF-LC): calcd for $\mathrm{C}_{117} \mathrm{H}_{144} \mathrm{Cl}_{2} \mathrm{~N}_{18} \mathrm{O}_{31}{ }^{2+} 1183.4806\left(\mathrm{MH}_{2}{ }^{2+}\right)$, found 1183.4811

Ac-KK-K(Vancomycin)-OH (25): HPLC purity $>95 \%, t_{\mathrm{R}}$ 4.6. (ES) $\mathrm{m} / z\left(\mathrm{MH}_{2}{ }^{2}\right.$ $\left.{ }^{+}\right)$939.7, $\left(\mathrm{MH}_{3}{ }^{3+}\right)$ 626.0, $\left(\mathrm{MH}_{4}{ }^{4+}\right)$ 469.8. HRMS exact mass (ESI microTOF-LC): calcd for $\mathrm{C}_{86} \mathrm{H}_{117} \mathrm{Cl}_{2} \mathrm{~N}_{15} \mathrm{O}_{28}{ }^{4+} 469.4387\left(\mathrm{MH}_{4}^{4+}\right)$, found 469.4365 .

POB2K-K-Dap-K(Vancomycin)-NHMe (27): HPLC purity $>95 \%, t_{\mathrm{R}}$ 5.3. (ES) $\mathrm{m} / z\left(\mathrm{MH}_{2}{ }^{2+}\right)$ 1162.4, $\left(\mathrm{MH}_{3}{ }^{3+}\right)$ 775.8, $\left(\mathrm{MH}_{4}{ }^{4+}\right)$ 582.1. HRMS exact mass (ESI microTOF-LC): calcd for calcd for $\mathrm{C}_{114} \mathrm{H}_{139} \mathrm{Cl}_{2} \mathrm{~N}_{18} \mathrm{O}_{31}{ }^{3+} 775.3071\left(\mathrm{MH}_{3}{ }^{3+}\right)$, found 775.3041.

POB2K-Dap-K-K(Vancomycin)-NHMe (28): HPLC purity $>95 \%, t_{\mathrm{R}}$ 5.2. (ES) $m / z\left(\mathrm{MH}_{2}{ }^{2+}\right)$ 1163.8, $\left(\mathrm{MH}_{3}{ }^{3+}\right) 775.8,\left(\mathrm{MH}_{4}{ }^{4+}\right)$ 582.1. HRMS exact mass (ESI microTOF-LC): calcd for $\mathrm{C}_{114} \mathrm{H}_{139} \mathrm{Cl}_{2} \mathrm{~N}_{18} \mathrm{O}_{31}{ }^{3+} 775.3071\left(\mathrm{MH}_{3}{ }^{3+}\right)$, found 775.3042 .

POB2K-Dap-Dap-K(Vancomycin)-NHMe (29): HPLC purity $>95 \%, t_{\mathrm{R}} 5.4$. (ES) $\mathrm{m} / z\left(\mathrm{MH}_{2}{ }^{2+}\right) 1142.7,\left(\mathrm{MH}_{3}{ }^{3+}\right) 761.9,\left(\mathrm{MH}_{4}{ }^{4+}\right)$ 571.6. HRMS exact mass (ESI microTOF-LC): calcd for $\mathrm{C}_{111} \mathrm{H}_{133} \mathrm{Cl}_{2} \mathrm{~N}_{18} \mathrm{O}_{31}{ }^{3+} 761.2915\left(\mathrm{MH}_{3}{ }^{3+}\right)$, found 761.2932.

POB2K-K-Dab-K(Vancomycin)-NHMe (30): HPLC purity $>95 \%, t_{\mathrm{R}}$ 5.2. (ES) $m / z\left(\mathrm{MH}_{2}{ }^{2+}\right)$ 1169.4, $\left(\mathrm{MH}_{3}{ }^{3+}\right)$ 780.5, $\left(\mathrm{MH}_{4}{ }^{4+}\right)$ 585.7. HRMS exact mass (ESI microTOF-LC): calcd for $\mathrm{C}_{115} \mathrm{H}_{141} \mathrm{Cl}_{2} \mathrm{~N}_{18} \mathrm{O}_{31}{ }^{3+} 779.9790\left(\mathrm{MH}_{3}{ }^{3+}\right)$, found 779.9766 .

POB2K-Dab-K-K(Vancomycin)-NHMe (31): HPLC purity $>95 \%, t_{\mathrm{R}} 5.4$. (ES) $m / z\left(\mathrm{MH}_{2}{ }^{2+}\right)$ 1169.9, $\left(\mathrm{MH}_{3}{ }^{3+}\right)$ 780.5, $\left(\mathrm{MH}_{4}{ }^{4+}\right)$ 585.6. HRMS exact mass (ESI
microTOF-LC): calcd for $\mathrm{C}_{115} \mathrm{H}_{141} \mathrm{Cl}_{2} \mathrm{~N}_{18} \mathrm{O}_{31}{ }^{3+} 779.9790\left(\mathrm{MH}_{3}{ }^{3+}\right)$, found 779.9761.

POB2K-Orn-Orn-K(Vancomycin)-NHMe (34): HPLC purity $>95 \%, t_{\mathrm{B}} 5.1$. (ES) $\mathrm{m} / z\left(\mathrm{MH}_{2}{ }^{2+}\right)$ 1170.7, $\left(\mathrm{MH}_{3}{ }^{3+}\right) 779.9,\left(\mathrm{MH}_{4}{ }^{4+}\right)$ 585.6. HRMS exact mass (ESI microTOF-LC): calcd for $\mathrm{C}_{115} \mathrm{H}_{141} \mathrm{Cl}_{2} \mathrm{~N}_{18} \mathrm{O}_{31}{ }^{3+} 779.9790\left(\mathrm{MH}_{3}{ }^{3+}\right)$, found 779.9788

POB2K-K-Orn-K(Vancomycin)-NHMe (32): HPLC purity $>95 \%, t_{\mathrm{R}}$ 5.1. (ES) $m / z\left(\mathrm{MH}_{2}{ }^{2+}\right)$ 1176.8, $\left(\mathrm{MH}_{3}{ }^{3+}\right)$ 785.0, $\left(\mathrm{MH}_{4}{ }^{4+}\right)$ 589.2. HRMS exact mass (ESI microTOF-LC): calcd for $\mathrm{C}_{116} \mathrm{H}_{144} \mathrm{Cl}_{2} \mathrm{~N}_{18} \mathrm{O}_{31}{ }^{4+} 588.7400\left(\mathrm{MH}_{4}{ }^{4+}\right)$, found 588.7418

POB2K-Orn-K-K(Vancomycin)-NHMe (33): HPLC purity $>95 \%, t_{\mathrm{R}}$ 5.2. (ES) $m / z\left(\mathrm{MH}_{2}{ }^{2+}\right)$ 1177.8, $\left(\mathrm{MH}_{3}{ }^{3+}\right)$ 785.2, $\left(\mathrm{MH}_{4}{ }^{4+}\right)$ 589.2. HRMS exact mass (ESI microTOF-LC): calcd for $\mathrm{C}_{116} \mathrm{H}_{143} \mathrm{Cl}_{2} \mathrm{~N}_{18} \mathrm{O}_{31}{ }^{3+} 784.6509\left(\mathrm{MH}_{3}{ }^{3+}\right)$, found 784.6490 .

POB2K-KK-Orn(Vancomycin)-NHMe (35): HPLC purity $>95 \%, t_{\mathrm{R}}$ 6.1. (ES) $\mathrm{m} / z\left(\mathrm{MH}_{2}{ }^{2+}\right)$ 1177.8, $\left(\mathrm{MH}_{3}{ }^{3+}\right)$ 785.2, $\left(\mathrm{MH}_{4}{ }^{4+}\right)$ 589.1. HRMS exact mass (ESI microTOF-LC): calcd for $\mathrm{C}_{116} \mathrm{H}_{143} \mathrm{Cl}_{2} \mathrm{~N}_{18} \mathrm{O}_{31}{ }^{3+} 784.6509\left(\mathrm{MH}_{3}{ }^{3+}\right)$, found 784.6497.

nC9CO-KKK-K(Vancomycin)-OH (36): HPLC purity $>95 \%, t_{\mathrm{R}}$ 5.2. (ES) $\mathrm{m} / z$ $\left(\mathrm{MH}_{2}{ }^{2+}\right)$ 1059.2, $\left(\mathrm{MH}_{3}{ }^{3+}\right) 706.2,\left(\mathrm{MH}_{4}{ }^{4+}\right)$ 529.8. HRMS exact mass (ESI microTOF-LC): calcd for $\mathrm{C}_{100} \mathrm{H}_{145} \mathrm{Cl}_{2} \mathrm{~N}_{17} \mathrm{O}_{29} 529.4937\left(\mathrm{MH}_{4}{ }^{4+}\right)$, found 529.4933

$n C 11 C O-K K K-K$ (Vancomycin)-OH (37). HPLC purity $>95 \%, t_{\mathrm{R}} 5.6$. (ES) $\mathrm{m} / z$ $\left(\mathrm{MH}_{2}{ }^{2+}\right)$ 1071.9, $\left(\mathrm{MH}_{3}{ }^{3+}\right)$ 715.0, $\left(\mathrm{MH}_{4}{ }^{4+}\right)$ 536.9. HRMS exact mass (ESI microTOF-LC): calcd for $\mathrm{C}_{102} \mathrm{H}_{147} \mathrm{Cl}_{2} \mathrm{~N}_{17} \mathrm{O}_{29} 1071.9958\left(\mathrm{MH}_{2}^{2+}\right)$, found 1072.0001

nC12CO-KKK-K-(Vancomycin)-OH (38): HPLC purity $>95 \%, t_{\mathrm{R}}$ 5.7. (ES) $\mathrm{m} /$ $z\left(\mathrm{MH}_{2}{ }^{2+}\right)$ 1078.9, $\left(\mathrm{MH}_{3}{ }^{3+}\right) 719.9,\left(\mathrm{MH}_{4}{ }^{4+}\right)$ 540.3. HRMS exact mass (ESI microTOF-LC): calcd for $\mathrm{C}_{103} \mathrm{H}_{150} \mathrm{Cl}_{2} \mathrm{~N}_{17} \mathrm{O}_{29} 719.6715\left(\mathrm{MH}_{3}{ }^{3+}\right)$, found 719.6710 .

nC10CO-GSKKK-K-(Vancomycin)-OH (39): HPLC purity $>95 \%, t_{\mathrm{R}} 5.4$. (ES) $\mathrm{m} / z\left(\mathrm{MH}_{2}{ }^{2+}\right)$ 1136.9, $\left(\mathrm{MH}_{3}{ }^{3+}\right)$ 758.7, $\left(\mathrm{MH}_{4}{ }^{4+}\right)$ 569.1. HRMS exact mass (ESI microTOF-LC): calcd for $\mathrm{C}_{106} \mathrm{H}_{154} \mathrm{Cl}_{2} \mathrm{~N}_{19} \mathrm{O}_{32} 758.3456\left(\mathrm{MH}_{3}{ }^{3+}\right)$, found 758.3477 .

POB-KKK-K-(Vancomycin)-OH (40): HPLC purity $>95 \%, t_{\mathrm{R}}$ 5.0. (ES) $\mathrm{m} / z$ $\left(\mathrm{MH}_{2}{ }^{2+}\right)$ 1079.3, $\left(\mathrm{MH}_{3}{ }^{3+}\right) 720.2,\left(\mathrm{MH}_{4}{ }^{4+}\right)$ 540.4. HRMS exact mass (ESI microTOF-LC): calcd for $\mathrm{C}_{103} \mathrm{H}_{133} \mathrm{Cl}_{2} \mathrm{~N}_{17} \mathrm{O}_{30}{ }^{2+} 1078.9385\left(\mathrm{MH}_{2}^{2+}\right)$, found 1078.9326.

POB-KK-K-(Vancomycin)-OH (41): HPLC purity $>95 \%, t_{\mathrm{R}} 5.9$. (ES) $\mathrm{m} / \mathrm{z}$ $\left(\mathrm{MH}_{2}{ }^{2+}\right)$ 1015.3, $\left(\mathrm{MH}_{3}{ }^{3+}\right)$ 677.3, $\left(\mathrm{MH}_{4}{ }^{4+}\right)$ 508.3. HRMS exact mass (ESI microTOF-LC): calcd for $\mathrm{C}_{97} \mathrm{H}_{123} \mathrm{Cl}_{2} \mathrm{~N}_{15} \mathrm{O}_{29}{ }^{4+} 507.9492\left(\mathrm{MH}_{4}{ }^{4+}\right)$, found 507.9498 .

POB2K-KKK-K-(Vancomycin)-OH (42): HPLC purity $>95 \%, t_{\mathrm{R}} 6.0$. (ES) $\mathrm{m} / \mathrm{z}$ $\left(\mathrm{MH}_{2}{ }^{2+}\right)$ 1241.3, $\left(\mathrm{MH}_{3}{ }^{3+}\right)$ 828.3, $\left(\mathrm{MH}_{4}{ }^{4+}\right)$ 621.5. HRMS exact mass (ESI microTOF-LC): calcd for $\mathrm{C}_{122} \mathrm{H}_{155} \mathrm{Cl}_{2} \mathrm{~N}_{19} \mathrm{O}_{33}{ }^{4+} 621.0097\left(\mathrm{MH}_{4}{ }^{4+}\right)$, found 621.0068 .

Determination of antimicrobial activity. Antimicrobial activity of compounds was tested against a number of bacterial strains by broth microdilution (BMD) assay with MIC determination, including S. aureus (MSSA ATCC $29213^{\circ m}$, MRSA $\operatorname{ATCC}^{\circ} 43300^{\mathrm{m}} \mathrm{\text { }}$, VISA NARSA NRS1, VISA NARSA NRS4), Streptococcus pneumoniae (MDR ATCC ${ }^{\circ} 700677^{\text {tm }}$ ) and Enterococcus faecium (MDR VanA ATCC ${ }^{\circ}$ $\left.51559^{\mathrm{m}}\right)$. ATCC strains were sourced from the American Type Culture Collection and NRS strains from NARSA (Network on Antimicrobial Resistance in S. aureus) via BEI Resources (www.beiresources.org). All compounds were prepared to 160 $\mu \mathrm{g} \mathrm{mL}^{-1}$ solution in water from a stock solution of $1 \mathrm{mM}$ concentration.

MIC assay. The compounds, along with standard antibiotics were serially diluted twofold across the wells of 96 -well non-binding surface (NBS) polystyrene plates (Corning 3641). (Note: We have found that MIC determinations in NBS plates give identical results to untreated polystyrene plates for most antibiotics (e.g. vancomycin, daptomycin, $\beta$-lactams, oxazolidinones), but for lipoglycopeptide antibiotics (dalbavancin, oritavancin and our vancapticins) where Clinical \& Laboratory Standards Institute (CLSI) guidelines recommend addition of $0.002 \%$ polysorbate 80 for MIC determination, values obtained in NBS plates with no additive match those obtained in untreated polystyrene plates with addition of $0.002 \%$ polysorbate 80 - Supplementary Table 12). Standards ranged from 64 to $0.03 \mu \mathrm{gL}^{-1}$ and compounds from 8 to $0.003 \mu \mathrm{g} \mathrm{mL}^{-1}$ with final assay volumes of $100 \mu \mathrm{L}$ per well. Gram-positive bacteria were cultured in Mueller Hinton broth (MHB) (Bactolaboratories, Cat. no. 211443) at $37^{\circ} \mathrm{C}$ overnight. A sample of each culture was then diluted 40 -fold in fresh MHB and incubated at $37^{\circ} \mathrm{C}$ for $2-3 \mathrm{~h}$. The resultant mid$\log$ phase cultures were added to the compound-containing 96-well plates to give a final cell density of $5 \times 10^{5}$ colony forming unit (CFU) $\mathrm{mL}^{-1}$. All the plates were covered and incubated at $37^{\circ} \mathrm{C}$ for $24 \mathrm{~h}$. MICs were the lowest concentration showing no visible growth

Serum reversal MIC assay. The compounds, along with standard antibiotics, tested in BMD-MIC assay as above, in the presence of a mixture of $50 \%$ human serum (Sigma-Aldrich) and 50\% MHB.

Surfactant reversal MIC assay. The compounds, along with standard antibiotics, were tested in BMD-MIC assay as above, in the presence of 1 and 5\% Survanta (beractant) suspension (Abbott Australasia Cat \# 1039.008; $25 \mathrm{mg} \mathrm{mL}^{-1}$ ) in MHB 
Lipid II ligand antagonism assay. All compounds were dissolved in $\mathrm{H}_{2} \mathrm{O}$. Bacillus subtilis ATCC $6633^{\text {mo }}$ NRS-231 was cultured in MHB at $37^{\circ} \mathrm{C}$ for $48 \mathrm{~h}$. A sample of each culture was then diluted 40 -fold in fresh MHB and incubated at $37^{\circ} \mathrm{C}$ for $18 \mathrm{~h}$. Compounds were added to each row of 96-well NBS plates (NBS, Corning 3641), in duplicate. The tripeptide $N, N^{\prime}$-diacetyl-L-Lys-D-Ala-D-Ala was serially diluted twofold across the compound-containing wells from 6400 to $3 \mu \mathrm{g} \mathrm{m} \mathrm{m}^{-1}$. To this the resultant mid-log phase cultures were diluted to the final concentration of $5 \times 10^{5}$ $\mathrm{CFU} \mathrm{mL} \mathrm{m}^{-1}$, then added to wells of the compound-containing plates. All the plates were covered and incubated at $37^{\circ} \mathrm{C}$ for $24 \mathrm{~h}$. The molar excess was determined as the ratio of [ligand]/[antibiotic] in the well containing the lowest ligand concentration that completely suppressed inhibition after $24 \mathrm{~h}$ incubation.

Time kill assay. S. aureus ATCC $43300^{\mathrm{mm}}$ (MRSA) was cultured in MHB (BactoLaboratories, Cat. No 211443 ) at $37^{\circ} \mathrm{C}$ overnight. A sample was then diluted 40 fold in fresh MHB and incubated at $37^{\circ} \mathrm{C}$ for $2-3 \mathrm{~h}$ until the culture reached early exponential phase $\left(\mathrm{OD}_{600}\right.$ of $\left.0.2-0.4\right)$. Vancapticin $24(1,0.25,0.015$ and $0.003 \mu \mathrm{g}$ $\left.\mathrm{mL}^{-1}\right)$ and vancomycin $\left(4,2,1\right.$ and $\left.0.5 \mu \mathrm{g} \mathrm{mL} L^{-1}\right)$ were serially diluted twofold across the wells of 96-well microtitre plates (NBS, Corning 3641) with a final volume of $50 \mu \mathrm{L}$, then combined with $50 \mu \mathrm{L}$ of bacterial inoculum (giving a final cell density of $5 \times 10^{5} \mathrm{CFU} \mathrm{mL}-1$ ) and incubated at $37^{\circ} \mathrm{C}$. Serial dilutions of the cultures were plated at each desired time point, using a multichannel pipette as follows: in row A of a 96-well plate, $50 \mu \mathrm{L}$ of sterile activated charcoal suspension $\left(25 \mathrm{mg} \mathrm{mL}^{-1}\right)$ was added, while $90 \mu \mathrm{L}$ of $0.9 \%$ sterile saline per well was added to the other rows. At selected time-points, $50 \mu \mathrm{L}$ aliquots were transferred from the time-kill assay plate to the first row containing the charcoal suspension and mixed well. The wells were further diluted 1 in $10(0.9 \%$ saline $)$ for the appropriate number of dilutions and $10 \mu \mathrm{L}$ of each dilution was spotted in duplicate onto LuriaBertani (LB) agar, then incubated overnight at $37^{\circ} \mathrm{C}$. The colonies in each spot were counted and used to calculate the number of viable $\mathrm{CFU} \mathrm{mL} \mathrm{m}^{-1}$ remaining in the original culture by considering the dilution factors (1:2 in charcoal, the serial dilution factor and the volume of the aliquot spotted).

Resistance frequency assay. The resistance frequency for Compound 19 was determined following literature procedures ${ }^{41,42}$.

Compound preparation: Compound 19 was prepared to $160 \mu \mathrm{g} \mathrm{mL}^{-1}$ solution in water from the given stock solution of $1 \mathrm{mM}$ concentration. Vancomycin was prepared to $1.28 \mathrm{mg} \mathrm{mL}^{-1}$ solution in water.

Antibacterial plate preparation: Tryptic soy broth (TSB) with $1 \%$ agarose and $0.002 \%$ Tween 80 was maintained at 45 to $50^{\circ} \mathrm{C}$ in a water bath. $160 \mathrm{~mL}$ of agarose was transferred to $200 \mathrm{~mL}$ glass bottle, maintaining the remaining agarose in the water bath. The appropriate amount of compound (calculated to give a final concentration 16-fold or 8-fold over MIC) was added to the $160 \mathrm{~mL}$ agarose sample [A]. A volume of $80 \mathrm{~mL}$ of agarose sample [A] was plated in four petri plates (duplicates/condition-neat, $10^{-1}$ ) with swirling to ensure that the bottom of the plate was coated equally. An additional $80 \mathrm{~mL}$ of fresh agarose was added to the remaining $80 \mathrm{~mL}$ of agarose [A] sample to achieve a twofold dilution to provide agarose sample [B]. Once again, $80 \mathrm{~mL}$ of agarose sample [B] was plated in four petri plates. This procedure was repeated until a range of concentrations of the antibacterial compound above the expected MIC was obtained. This method was done individually for every antibacterial compound under study. Agarose plate MIC values used for this study were determined to be $1 \mu \mathrm{g} \mathrm{mL}^{-1}$ for vancomycin and $0.06 \mu \mathrm{g} \mathrm{mL}^{-1}$ for compound 19 .

\section{Plate culture for titre of $\mathbf{1 8} \mathrm{h}$ stationary phase and resistance frequency:} Bacteria were subcultured at $37^{\circ} \mathrm{C}$ overnight with shaking at $220 \mathrm{rpm}$. The bacterial culture was serially diluted in MHB to achieve a $10^{-1}$ to $10^{-8}$ dilution series. The three last dilutions $\left(10^{-6}, 10^{-7}\right.$ and $\left.10^{-8}\right)$ were used to determine the titre of the culture. An aliquot of $100 \mu \mathrm{L}(10 \mu \mathrm{L}$ in some cases) of these three dilutions were added to compound-free agar petri plates. This was done in duplicate and the plates were incubated overnight at $37^{\circ} \mathrm{C}$. Resultant separated visible colonies were counted; those colonies that grow together were not included to determine the titre of the culture. An aliquot of $100 \mu \mathrm{L}$ of the neat (undiluted) stationary-phase culture and $10^{-1}$ dilution was plated separately onto the agar plate containing each concentration of antibacterial compound. The plates were incubated overnight at $37^{\circ} \mathrm{C}$.

Detection and analysis: The colonies were counted after $24 \mathrm{~h}$. The resistance frequency is determined by dividing the number of colonies obtained on the plates containing the antibacterial agent by the number of cells plated.

Resistance induction assay. A resistance induction assay was conducted for vancomycin, daptomycin, compound 17 and compound $24^{43}$.

S. aureus ATCC $43300^{\circ m}$ was grown in Mueller Hinton broth supplemented with $50 \mu \mathrm{g} \mathrm{mL}^{-1}$ of $\mathrm{CaCl}_{2}$. The bacterial culture was incubated at $37^{\circ} \mathrm{C}$ in a shaker at $195 \mathrm{rpm}$.
Viability testing: The mid $\log S$. aureus growth culture was serially diluted and plated on a solid LB agar plates in quadruplicates and incubated at $37^{\circ} \mathrm{C}$ overnight to determine viable colony count.

Antimicrobial broth microdilution MICs and plate preparation: The initial determination of the compound MICs were taken from the literature and empirically measured. Doubling MIC dilutions were prepared in Cation-adjusted Mueller-Hinton broth (Ca-MHB) in NBS 96-well plates (NBS, Corning 3641) with columns 11 and 12 allocated for bacterial culture without the antimicrobial and $\mathrm{Ca}$ MHB media. The starting MIC ranges were $20 \mu \mathrm{g} \mathrm{mL}^{-1}$ to $0.08 \mu \mathrm{g} \mathrm{mL} L^{-1}$ for daptomycin, $32 \mu \mathrm{g} \mathrm{mL}^{-1}$ to $0.06 \mu \mathrm{g} \mathrm{mL}^{-1}$ for vancomycin and $0.5 \mu \mathrm{g} \mathrm{mL}^{-1}$ to $0.001 \mu \mathrm{g}$ $\mathrm{mL}^{-1}$ for both vancapticins with $100 \mu \mathrm{L}$ of the dilutions added to the plate. MRSA culture in mid log growth with 0.6 optical density at $600 \mathrm{~nm}\left(\mathrm{OD}_{600}\right)$ was diluted to an equivalence of $10^{5} \mathrm{CFU} \mathrm{mL} \mathrm{m}^{-1}$ and $100 \mu \mathrm{L}$ was added to the antimicrobial containing plate. The plate was then incubated at $37^{\circ} \mathrm{C}$ overnight.

Daily antimicrobial MIC plate preparation: After overnight incubation, the growth of the $S$. aureus (MRSA) culture was determined by reading at $\mathrm{OD}_{600}$ on the Epoch microplate spectrophotometer and $0.1 \mathrm{OD}_{600}$ was the chosen cut-off determining growth vs. no growth. The sample selection of $S$. aureus and preparation was carried out as previously described ${ }^{43}$ with $10 \mu \mathrm{L}$ of the sub-lethal MIC $S$. aureus cultures (i.e. the maximum antibiotic concentration with $\mathrm{OD}_{600} \geq 0.1$ ) diluted in $10 \mathrm{~mL}$ of Ca-MHB for the following day's MIC plate. Doubling dilutions were supplemented with intermediate MICs to reduce the MIC difference and provide a ladder for non-susceptible isolates for the 20 day period with an average overnight incubation of $19 \mathrm{~h}$ at $37^{\circ} \mathrm{C}$. The non-susceptible isolates were grown overnight at $37^{\circ} \mathrm{C}$ with shaking before being preserved in $20 \%$ glycerol and as a pellet (stored frozen at $-80^{\circ} \mathrm{C}$ ).

Cytotoxicity assay. Compound cytotoxicity was evaluated against HepG2 (ATCCHB-8065 liver hepatoceullular carcinoma) and HEK293 (ATCC CRL-1573, embryonic kidney) human cell lines using standard (3-(4,5-dimethylthiazol-2-yl) -2,5-diphenyltetrazolium bromide (MTT) assay protocol with slight changes. In brief, HepG2 and HEK293 cells (assessed annually for mycoplasma contamination) were seeded as $1.5 \times 10^{4}$ cells per well in a clear 96-well tissue culture treated plate in a final volume of $100 \mu \mathrm{L}$ in Dulbecco's Modified Eagle Medium (DMEM) (GIBCO-Invitrogen \#11995-073), in which 1\% of FBS was added. Cells were incubated for $24 \mathrm{~h}$ at $37^{\circ} \mathrm{C}, 5 \% \mathrm{CO}_{2}$ to allow cells to attach to the plates. Compounds prepared at $100 \mu \mathrm{M}$ to $0.046 \mu \mathrm{M}$ in threefold dilutions were added into each well and incubated for $24 \mathrm{~h}$ at $37^{\circ} \mathrm{C}, 5 \% \mathrm{CO}_{2}$. After the incubation, $0.4 \mathrm{mg} \mathrm{mL}^{-1} \mathrm{MTT}$ (3-(4,5-dimethylthiazol-2-yl)-2,5-diphenyltetrazolium bromide) (Invitrogen) was added to each well. The plates were then incubated for $2 \mathrm{~h}$ at $37^{\circ} \mathrm{C}, 5 \% \mathrm{CO}_{2}$. The media was removed, and purple formazan crystals were resuspended in $60 \mu \mathrm{L}$ of DMSO. The absorbance was read at $570 \mathrm{~nm}$ using a Polarstar Omega plate reader. The data was then analysed by Prism software. Results are presented as the average percentage of control \pm S.D. for each set of duplicate wells using the following equation: percent viability $=\left(\mathrm{ABS}_{\mathrm{TEST}}-\mathrm{ABS}_{\text {POSITIVE CTRL }} / \mathrm{ABS}_{\mathrm{UNTREATED}}-\mathrm{ABS}\right.$ POSITIVE CTRL $) \times 100$.

Haemolysis assay. Haemolytic activity was measured as previously described with slight modifications ${ }^{44,45}$. Fresh human venal blood was collected from healthy volunteers and pretreated with the anticoagulant sodium citrate. Serial twofold dilutions of each antibiotic, dissolved in $0.9 \% \mathrm{NaCl}$ solution, were added to fresh human whole blood (50\% final, vol:vol) to the final volume of $80 \mu \mathrm{L}$ and incubated at $37^{\circ} \mathrm{C}$ for $3 \mathrm{~h}$ on a horizontal shaker at $200 \mathrm{rpm}$. For negative and positive controls, human whole blood in $0.9 \% \mathrm{NaCl}$ solution $\left(A_{\text {blank }}\right)$ and in $\mathrm{sdH}_{2} \mathrm{O}\left(A_{\text {water }}\right)$ were used, respectively. After incubation, both test and $A_{\text {blank }}$ were mixed with 1 $\mathrm{mL} 0.9 \% \mathrm{NaCl}$ solution, or $\mathrm{sdH}_{2} \mathrm{O}$ for the complete hydrolysis $A_{\text {water }}$. After centrifugation of samples at $2500 \mathrm{rpm}(700 \times g)$ for $5 \mathrm{~min}$, the release of haemoglobin was monitored by measuring the absorbance $\left(A_{\text {sample }}\right)$ of the supernatant at $540 \mathrm{~nm}$ using BMG Labtech PolarStar Omega multimode reader. The percentage of haemolysis was calculated according to the equation:

$$
\% \text { haemolysis }=\left[\left(A_{\text {sample }}-A_{\text {blank }}\right) /\left(A_{\text {water }}-A_{\text {blank }}\right)\right] \times 100
$$

Critical micelle concentration assay. CMCs were determined as previously described $^{46}$ with a higher throughput modification. Briefly, a cascade dilution of each antibiotic was performed in a low binding polypropylene V-bottom shaped 96-well plates in the presence of $0.2 \mathrm{M} \mathrm{NaCl}$ solution across 12 concentrations ranging from 1000 to $0.1 \mu \mathrm{M}$, except the control melittin (100 to $0.01 \mu \mathrm{M})$. An identical cascade dilution was performed for the neutral detergent Triton X-100 and the anionic detergent sodium dodecyl sulphate (SDS) starting from $0.1 \%$ down to $0.00001 \%$ (vol:vol for Triton X-100 and wt:vol for SDS). An aliquot of 6diphenyl-1,3,5-hexatriene (DPH) in DMSO was added in each well to yield the final DPH concentration of $5 \mu \mathrm{M}$. The reaction mixtures were mixed for $30 \mathrm{~s}$ and transferred in horizontal triplicate $(25 \mu \mathrm{L}$ per well) into a black falcon 384 -well plate. The 384-well plate was then sealed, wrapped up in aluminium foil and incubated for $30 \mathrm{~min}$ at room temperature. The fluorescence intensity was 
monitored in real time using a BMG Labtech PolarStar Omega multimode reader fitted with 360-10 and 430-10 excitation and emission filters respectively, at an excitation wavelength of $360 \mathrm{~nm}$ and an emission wavelength of $430 \mathrm{~nm}$.

Membrane depolarisation assay. Antibiotic-induced bacterial cytoplasmic membrane depolarisation was determined using the fluorescent dye 3,3-dipropylthiacarbocyanine diSC3(5) (Sigma Aldrich, Australia) as previously described ${ }^{37}$. Briefly, early exponential phase cells were pelleted and washed twice in $10 \mathrm{mM}$ HEPES buffer ( $\mathrm{pH}$ 7.4) containing $50 \mu \mathrm{g} \mathrm{mL}^{-1}$ of $\mathrm{CaCl}_{2}$ and $5 \mathrm{mM}$ Glucose, and then re-suspended in the same buffer $\left(2 \times 10^{8} \mathrm{CFU} \mathrm{mL}^{-1}\right)$. diSC3(5) was added to a final concentration of $1.5 \mu \mathrm{M}$ and incubated at room temperature in the dark to enable dye uptake and fluorescence quenching. After $30 \mathrm{~min}$, cells were diluted 50fold in assay buffer and $45 \mu \mathrm{L}$ of cells were added to a 384-well black walled polystyrene plate (Corning, CLS3573) (Note: NBS plates were not employed, and no polysorbate- 80 was added to avoid potential effects on membrane permeability, or interference with fluorescence as previously reported ${ }^{37}$. The MICs of compounds in polystyrene plates are listed in Supplementary Table 12). Background data was collected before adding compounds using a Tecan Infinite ${ }^{\circledR}$ m1000 Pro Multi-mode reader (excitation/emission 612/665 nm) to ensure fluorescence quenching. Compounds were added to a final concentration of $16 \mu \mathrm{gL}^{-1}$ and fluorescence was monitored for $30 \mathrm{~min}$. Data were corrected by subtraction of background response (diSC3(5) in the presence of untreated cells, no compound). Note that the MIC values for oritavancin and compound 17 increase to $1 \mu \mathrm{gL}^{-1}$, and compound 24 to $2 \mu \mathrm{g} \mathrm{mL}^{-1}$, in polystyrene plates. Each sample was tested in quadruplicate and independent assays were performed twice showing similar results. Data were analysed and presented using Prism software.

Membrane permeability assay. To evaluate the ability of the compounds to disrupt the cytoplasmic membrane integrity, the membrane impermeable fluorescent DNA intercalating dye propidium iodide (PI) was used. Early exponential phase cells were pelleted and washed twice in $10 \mathrm{mM}$ HEPES buffer (pH 7.4) containing $50 \mu \mathrm{g} \mathrm{mL}^{-1}$ of $\mathrm{CaCl}_{2}$ and $5 \mathrm{mM}$ glucose, and then re-suspended in the same buffer $\left(4 \times 10^{8} \mathrm{CFU} \mathrm{mL} \mathrm{mL}^{-1}\right)$. Cell suspension was added to a 384-well black walled polystyrene plate (Corning, CLS3573) containing compounds, giving a final concentration of $16 \mu \mathrm{g} \mathrm{mL}^{-1}$. After $1 \mathrm{~h}$ incubation at $37^{\circ} \mathrm{C}, 5 \mu \mathrm{g} \mathrm{mL} L^{-1}$ of PI was added and fluorescence was monitored for 90 min using a Tecan Infinite ${ }^{\circledR}$ m1000 Pro Multi-mode reader (excitation/emission 535/620 nm). Data were corrected by subtraction of fluorescence signal arising from untreated cells in the presence of PI. Note that the MIC values for oritavancin and compound 17 increase to $1 \mu \mathrm{gL}^{-1}$, and compound 24 to $2 \mu \mathrm{gL}^{-1}$, in polystyrene plates. Each sample was tested in quadruplicate and independent assays were performed twice showing similar results. Data was analysed and presented using Prism software.

ITC for assessment of ligand binding and dimerisation. Calorimetric experiments were performed on a MicroCal Omega Auto-iTC200 Isothermal Titration Calorimeter (GE Healthcare, Australia), at $298 \mathrm{~K}$, with a $10 \mu \mathrm{cal} \mathrm{s}^{-1}$ reference power and stirring speed of $1000 \mathrm{rpm}$. All samples were prepared in $0.1 \mathrm{M} \mathrm{NaOAc}$, pH 5.0 buffer. Each experiment consisted of sequential injections into the calorimeter cell $(0.2 \mathrm{~mL})$ with $240 \mathrm{~s}$ equilibration intervals. Corrections of small heat effects from separate blank titrations were made prior to analysis. Data were processed using the MicroCal Origin 7.0 software package provided with the instrument to fit a single site binding model or dissociation model to estimate the association constant $\left(K_{\mathrm{a}}\right)$, enthalpy $(\Delta H)$, entropy $(\Delta S)$ and stoichiometry $(N)$. The Gibbs free energy change $(\Delta G)$ was calculated using the Gibbs-Helmholz thermodynamic equation, (1):

$$
\Delta G=-R T \ln K
$$
Kelvin.

Where $R$ is the ideal gas constant $\left(8.31 \mathrm{~J} \mathrm{~mol}^{-1} \mathrm{~K}^{-1}\right)$ and $T$ is the temperature in

Single site binding: Ligand binding experiments consisted of 12 sequential injections $(2 \mu \mathrm{L}$ per injection, first injection of $0.5 \mu \mathrm{L})$ of ligand $(400 \mu \mathrm{M}$, concentration 14 -fold to 20 -fold higher than the antibiotic concentration) into the calorimeter cell containing the antibiotic (monomer solution $25 \mu \mathrm{M}$ for vancomycin and $40 \mu \mathrm{M}$ for vancapticins). Antibiotic concentration was selected to avoid self-dimerisation.

Dimer-monomer dissociation: Dissociation experiments involved 13 sequential injections ( $3 \mu \mathrm{L}$ per injection, first injection of $0.5 \mu \mathrm{L})$ of concentrated $(3.0 \mathrm{mM})$ antibiotic solutions titrated to buffer only. Dissociation experiments involving ligand maintained a constant concentration of excess ligand $(9.0 \mathrm{mM})$ dissolved in buffer in both the calorimeter cell and titration syringe to ensure that antibiotic molecules were predominantly in their ligand-complexed form.

SPR membrane binding assay. SPR experiments were performed using a BIAcore 3000 (GE Health) instrument with a Biacore vesicle capture L1 sensor chip. DMPC (1,2-dimyristoyl-sn-glycero-3-phosphocholine) and DMPG (1,2-dimyristoyl-snglycero-3-phosphoglycerol) were purchased from Avanti Polar Lipids. Small unilamellar vesicles (SUV) were prepared in phosphate buffered saline (PBS) (pH 7.4) by sonication and extrusion. In brief, lipids were dissolved in chloroform in $25 \mathrm{~mL}$ round-bottom flasks, and then deposited as a thin film by removal of the solvent (chloroform) under reduced pressure on a rotary evaporator and dried under high vacuum for at least $2 \mathrm{~h}$. PBS was then added into each flask to give a suspension, which was sonicated for 5 cycles of $5 \mathrm{~min}$ each. The suspension was passed $17 \times$ through a 50-nm polycarbonate filter in an Avestin Lipofast Basic extrusion apparatus to give a translucent solution of vesicles, which should possess a mean diameter of $50 \mathrm{~nm}$. The SUVs were injected across the L1 sensor chip for $30 \mathrm{~min}$ at a flow rate of $2 \mathrm{~mL} \mathrm{~min}^{-1}$ to form a supported lipid bilayer. The coverage of the lipid bilayer was determined from the extent of non-specific binding of bovine serum albumin $\left(0.1 \mathrm{mg} \mathrm{mL}^{-1}\right.$ in PBS, 5 min injection). A series of concentrations of vancomycin and vancapticins were passed sequentially over the different phospholipid-containing flow cells at a flow rate of $30 \mu \mathrm{L} \mathrm{min}^{-1}$ for $180 \mathrm{~s}$. The amount of antibiotic bound at equilibrium just before the end of the injection was corrected by subtraction of the bulk-refractive index difference observed at the beginning and the end of each injection. After each injection cycle, the lipid surface was regenerated with $20 \mathrm{mM} 3$-[(3-cholamidopropyl)dimethylammonio]-1-propanesulfonate (CHAPS) and a fresh lipid bilayer was loaded as described above. All assays were carried out at $25^{\circ} \mathrm{C}$ in triplicate. The equilibrium binding response values obtained were normalised by dividing the average observed response (RU) by the molecular weights (MW) of each compound, i.e. $\mathrm{RU}_{\text {adjusted }}=100 \times \mathrm{RU} / \mathrm{MW}$.

Peptidoglycan inhibition assay. The cell-free particulate fraction of Bacillus megaterium KM (ATCC $13632^{\mathrm{m}}$ ) was used to catalyse the polymerisation of peptidoglycan from UPD-linked precursors in vitro following literature procedures ${ }^{47}$. B. megaterium was grown in the medium containing $1 \%(\mathrm{w} / \mathrm{v})$ tryptone (Difco-Bacto), $0.5 \%(\mathrm{w} / \mathrm{v})$ yeast extract (Difco-Bacto), $0.25 \%(\mathrm{w} / \mathrm{v}) \mathrm{K}_{2} \mathrm{HPO}_{4}$ and $0.5 \%(\mathrm{w} / \mathrm{v})$ glucose with $\mathrm{pH} 7.2$. Bacteria were harvested when the density had reached to $0.4 \mathrm{mg}$ dry weight $\mathrm{mL}^{-1}$ and washed in the buffer $0.05 \mathrm{M}$ Tris-HCl (pH 7.8) containing $10 \mathrm{mM} \mathrm{MgCl}_{2}$ by centrifugation at $6000 \times g$ for $10 \mathrm{~min}$ at $4{ }^{\circ} \mathrm{C}$. All subsequent manipulations were carried out on ice. The bacteria were resuspended in the same buffer at a density of $50 \mathrm{mg}$ dry weight $\mathrm{mL}^{-1}$, and then subjected to three freeze/thaw cycles. Bacteria were then homogenised by using a glass homogeniser at $4{ }^{\circ} \mathrm{C}(2 \times 10 \mathrm{~min})$. The broken cell suspension was centrifuged at $6000 \times g$ for $10 \mathrm{~min}$ at $4{ }^{\circ} \mathrm{C}$. The supernatant (Supernatant 1 ) which contained the unbroken cells and the majority of the cell walls was collected. The pellet was resuspended in the same buffer and re-centrifuged at $6000 \times g$ for $10 \mathrm{~min}$ at $4{ }^{\circ} \mathrm{C}$, and the supernatant (Supernatant 2) was collected. The two supernatants (Supernatant 1 and Supernatant 2) were combined and centrifuged at 20,500 rpm $(38,000 \times g)$ for $1 \mathrm{~h}$ at $4^{\circ} \mathrm{C}$. The pellet, consisting mainly of membrane fragments together with some cell wall material, was washed once with the same buffer and finally resuspended in $0.05 \mathrm{M}$ Tris- $\mathrm{HCl}(\mathrm{pH} 7.8)$ containing $10 \mathrm{mM} \mathrm{MgCl}_{2}$. In vitro peptidoglycan synthesis was performed by mixing the following contents in a final volume of $20 \mu \mathrm{L}: 50 \mathrm{mM}$ Tris- $\mathrm{HCl}(\mathrm{pH} 7.8), 10 \mathrm{mM} \mathrm{MgCl}_{2}, B$. megaterium membrane faction (around 40 to $50 \mu \mathrm{g}$ protein), $0.4 \mathrm{mM}$ uridine $5^{\prime}$-diphospho $N$-acetyl muramoyl-L-alanyl-D- $\gamma$-glutamyl-L-lysyl-D-alanyl-D-alanine (UDP-MurNAc-pentapeptide, The University of Warwick, UK), $6.5 \mu \mathrm{M}\left[{ }^{14} \mathrm{C}\right] \mathrm{UDP}-\mathrm{N}$-acetylglucosamine (UDP- $\left[{ }^{14} \mathrm{C}\right] \mathrm{GlcNAc}$, American Radiolabeled Chemicals Inc, $25 \mu \mathrm{ci}$, 11.1 GBq mmol${ }^{-1}, 0.1 \mathrm{mci} \mathrm{mL}^{-1}$ ) and vancapticins at final concentrations of 0 , $0.03,0.1,1,3$ and $10 \mu \mathrm{gL}^{-1}$. The reaction mixtures were incubated at RT for $3 \mathrm{~h}$ and placed in a boiling water bath for $3 \mathrm{~min}$ to inactivate the enzymes. $5 \mu \mathrm{L}$ of each sample was separated using TLC on silica gel plates (TLC Silica gel $60 \mathrm{~F}_{254}, 20 \times 20$ $\mathrm{cm}$, Merck KGaA, Germany) for $2 \mathrm{~h}$ in isobutyric acid $/ 1 \mathrm{M} \mathrm{NH}_{4} \mathrm{OH}(5 / 3, \mathrm{v} / \mathrm{v})$. The TLC plates were then dried and exposed to a phosphorimaging screen (GE Healthcare, Australia) for 1 week and scanned using a Typhoon 8600 (GE Healthcare, Australia). Integrated density value (IDV) of each band on silica gel was analysed using AlphaEase FC software (AlphaImager 2200). The change of peptidoglycan or Lipid II were calculated as percent from the IDV values of the control (without any antibiotic or compound).

Human plasma stability assay. Compound stability in human plasma was performed as previously reported ${ }^{48}$, with modifications. Briefly, test compounds $(20 \mu \mathrm{M})$ were prepared from a $0.2 \mathrm{mM} \mathrm{H}_{2} \mathrm{O}$ stock solution $(40 \mu \mathrm{L}$ in $400 \mu \mathrm{L}$ assay volume) except eucatropine, which was $300 \mu \mathrm{g} \mathrm{mL}^{-1}$ in $100 \%$ DMSO $(10 \mu \mathrm{L}$ in 400 $\mu \mathrm{L}$ assay volume equivalent to $23 \mu \mathrm{M}$ ). The precipitating solution was prepared by adding $5 \mu \mathrm{L}$ of $10 \mathrm{mM}$ carbutamide in DMSO to $100 \mathrm{~mL}$ acetonitrile (final concentration: $135.5 \mathrm{ng} \mathrm{mL}^{-1}$ or $0.5 \mu \mathrm{M}$ carbutamide). The human plasma sample (pooled normal human plasma sodium heparin anticoagulant, $2 \mu \mathrm{L}$, Cat No.: HMPLNAHP, BioReclamation) and phosphate-buffer saline (PBS, pH 7.4 isotonic) were pre-heated at $37^{\circ} \mathrm{C}$ for $30 \mathrm{~min} .40 \mu \mathrm{L}$ of test compounds $(0.2 \mathrm{mM})$ were added to protein-low binding Eppendorf tubes, $160 \mu \mathrm{L}$ of buffer was added, and the mixture was vortexed. For eucatropine, $10 \mu \mathrm{L}$ of eucatropine $\left(300 \mu \mathrm{g} \mathrm{mL}^{-1}\right)$ was added to a protein-low binding Eppendorf tube, $190 \mu \mathrm{L}$ of buffer was added, and the mixture was vortexed. In each case, $200 \mu \mathrm{L}$ of plasma was added and the resultant mixture vortexed. For the initial time point (reaction time $t=0 \mathrm{~h}$ ), $50 \mu \mathrm{L}$ of sample was immediately transferred into a protein-low binding Eppendorf tube and quenched with $150 \mu \mathrm{L}$ of the ice-cold precipitating solution, followed by 
vortexing and subsequent storage at $4^{\circ} \mathrm{C}$. For the remaining time points, the plasma solution was incubated and shaken $(150 \mathrm{rpm})$ at $37^{\circ} \mathrm{C} .50 \mu \mathrm{L}$ aliquots were collected at time points of $0,1,3,6$ and $24 \mathrm{~h}$ and quenched with $150 \mu \mathrm{L}$ the ice-cold precipitating solution. All samples were placed in a $4{ }^{\circ} \mathrm{C}$ fridge for $30 \mathrm{~min}$ then centrifuged at $14,000 \times g$ for $8 \mathrm{~min}$ at $4{ }^{\circ} \mathrm{C}$. The supernatant $(100 \mu \mathrm{L})$ was transferred to a glass vial insert and stored at $4{ }^{\circ} \mathrm{C}$ until LC-MS/MS analysis. The percentage of test compounds remaining at the individual time points relative to sample at time point $0 \mathrm{~h}$ were reported.

Glutathione stability assay. The stability of compounds in the presence of physiological concentrations of glutathione was assessed according to the protocol below: $20 \mu \mathrm{L}$ of a $1 \mathrm{mM}$ stock solution of the test compound was added to $180 \mu \mathrm{L}$ of glutathione (reduced form) PBS solution within a plastic HPLC insert, providing a solution with a final concentration of $100 \mu \mathrm{M}$ of compound and either $5 \mathrm{mM}$ or 0.5 $\mathrm{mM}$ in glutathione. The sample was placed in a HPLC sampling rack and sampled at hourly intervals up to $10 \mathrm{~h}$. Care was taken to prepare the sample immediately before injection. The UV area was then plotted for the loss of compound against time. Percentages were plotted relative to total vancomycin derivative at $0 \mathrm{~h}$. Results are shown in Supplementary Fig. 4.

Microsomal stability assay. Performed by CDCO, Monash University, Australia.

Incubation methods: The solubility of test compounds and their recovery from the incubation matrix were confirmed prior to the metabolic assay. The metabolic stability assay was performed by incubating each test compound $(1 \mu \mathrm{M})$ with human (Xenotech, Lot \#1210057) and mouse (Xenotech, Lot \#1110071) liver microsomes at $37^{\circ} \mathrm{C}$ and $0.4 \mathrm{mg} \mathrm{mL}^{-1}$ protein concentration. The metabolic reaction was initiated by the addition of a nicotinamide adenine dinucleotide phosphate (NADPH)-regenerating system (i.e. NADPH is the cofactor required for cytochrome $\mathrm{P} 450$-mediated metabolism) and quenched at various time points over the $60 \mathrm{~min}$ incubation period by the addition of acetonitrile. Control samples (containing no NADPH) were included (and quenched at 2, 30 and $60 \mathrm{~min}$ ) to monitor for potential degradation in the absence of cofactors. Concentrations of each test compound in quenched samples were determined by ultra performance liquid chromatography mass spectrometry (UPLC-MS) (Waters/Micromass Xevo triple quadrupole mass spectrometer). Note: Due to the minimal degradation of test compounds in this assay, a metabolite search was not conducted. In addition, glucuronidation was not considered in this study and may require further assessment using alternative test systems.

Calculations: Test compound concentration vs. time data were fitted to an exponential decay function to determine the first-order rate constant for substrate depletion. In cases where clear deviation from first-order kinetics was evident, only the initial linear portion of the profile was utilised to determine the degradation rate constant $(k)$. Each substrate depletion rate constant was then used to calculate: (1) a degradation half-life, where $t_{1 / 2}=\ln (2) k^{-1} ;(2)$ an in vitro intrinsic clearance value, where $\mathrm{CL}_{\text {int,in vitro }}=k\left[\text { microsomal protein content }\left(0.4 \mathrm{mg} \mathrm{mL}^{-1}\right)\right]^{-1} ;(3)$ a predicted in vivo hepatic intrinsic clearance value, where $\mathrm{CL}_{\text {int }}=\mathrm{CL}_{\text {int, in vitro }} \times$ [liver mass $(\mathrm{g}) /$ body weight $(\mathrm{kg})] \times[$ microsomal protein $(\mathrm{mg}) /$ liver mass $(\mathrm{g})]$; and $(4)$ a predicted in vivo hepatic extraction ratio, where $E_{\mathrm{H}}=\mathrm{CL}_{\text {blood }} Q^{-1}=\mathrm{Cl}_{\text {int }}\left[Q+\mathrm{Cl}_{\text {int }}\right]^{-1}$.

Scaling parameters assumed were: human liver mass $20 \mathrm{~g}$ liver / $\mathrm{kg}$ body weight $^{49}$, human microsomal protein $40 \mathrm{mg} \mathrm{g}^{-1}$ liver mass ${ }^{49}, 50$, human hepatic blood flow (Q) $20.7 \mathrm{~mL} \mathrm{~min}^{-1} \mathrm{~kg}$ body weight ${ }^{-151}$, mouse liver mass $87.5 \mathrm{~g}$ liver / $\mathrm{kg}$ body weight ${ }^{51}$, mouse microsomal protein $45 \mathrm{mg} \mathrm{g}^{-1}$ liver mass ${ }^{51}$, mouse hepatic blood flow $(Q) 90 \mathrm{~mL} \mathrm{~min}^{-1} \mathrm{~kg}$ body weight ${ }^{-1}{ }^{51}$.

In vivo pharmacokinetics. Performed by WuXi AppTec (Shanghai) Co., Ltd. Seven to 9-week-old male CD1 mice (SLAC Laboratory Animal Co. Ltd., Shanghai, China) weighing 25-35 g were acclimated for approximate 3 days before being used in the study. Animals are group housed during acclimation and in-life study in compliance with the National Research Council 'Guide for the Care and Use of Laboratory Animals.' The animal room environment is controlled (target conditions: temperature 18 to $26^{\circ} \mathrm{C}$, relative humidity $30-70 \%, 12 \mathrm{~h}$ artificial light and $12 \mathrm{~h}$ dark) with temperature and relative humidity monitored daily. Animals were deprived of food for approximately $16 \mathrm{~h}$ before formulation administration then allowed access to Certified Rodent Diet (Catalogue \# M-01F, Shanghai SLAC Laboratory Animal Co. Ltd.) ad libitum $4 \mathrm{~h}$ post dosing. Water was autoclaved before being provided to the animals ad libitum. Formulations of compounds were prepared on the morning of the dosing day. The formulation for the IV group was filtered with filter of $0.22 \mu \mathrm{m}$ before being dosed to animals. After dose formulation preparation, duplicate $50 \mu \mathrm{L}$ aliquots were removed from each dose formulation for use in dose validation. For each compound studied, three mice were dosed intravenously (IV) administered to each animal via tail vein per facility SOPs using test article formulated in deionised water at $1 \mathrm{mg} \mathrm{mL}^{-1}$ with a dose volume of $2 \mathrm{mg} \mathrm{mL}$ -1 , providing a dose of $2 \mathrm{mg} \mathrm{mL}^{-1}$ (based on free base concentration). An additional three mice were dosed subcutaneously (SC) administered to each animal via subcutaneous bolus on each animals' back per facility SOPs using test article formulated in deionised water at $2 \mathrm{mg} \mathrm{mL}^{-1}$ with a dose volume of $5 \mathrm{mg} \mathrm{mL}^{-1}$, providing a dose of $10 \mathrm{mg} \mathrm{mL}^{-1}$. All animals were killed at the last study time point (100\% $\mathrm{CO}_{2}$ was introduced into the animal box).

Sample collection: Plasma samples were collected as the following target times after each dose administration: IV Sampling Time points (hours post dosing): 0, $0.083,0.25,0.5,1,2,4,8$ and 24 . SC Sampling Time points (hours post dosing): 0 , $0.25,0.5,1,2,4,8$ and 24 . Approximately $30 \mu \mathrm{L}$ blood was obtained via submandibular or saphenous vein for the first several time points. For the last time point, samples were collected via cardiac puncture while the mouse was under anaesthesia. All blood samples were transferred into pre-chilled plastic microcentrifuge tubes containing $2 \mu \mathrm{L}$ of ethylenediaminetetraacetic acid dipotassium salt (K2-EDTA) $(0.5 \mathrm{M})$ as anticoagulant and placed on wet ice until centrifugation. Harvested blood samples were centrifuged within $30 \mathrm{~min}$ of collection at $7000 \mathrm{rpm}$ $(8546 \times g) 4^{\circ} \mathrm{C}$ for about $10 \mathrm{~min}$. After centrifugation, plasma was transferred into another pre-labelled and pre-chilled polypropylene microcentrifuge tubes, then quick-frozen over dry ice and stored at $-70 \pm 10^{\circ} \mathrm{C}$ until LC/MSMS analysis.

Sample analysis: Dosing formulations verification: Aliquots of the formulations were collected in the middle position of each dose formulation in duplicate. A LCUV method was developed with a calibration curve consisting of six calibration standards. The concentrations of the test compound in dose formulation samples were determined by the LC-UV method. Acceptance criteria for an analytical run at least of five of six calibration standards should be within $20 \%$ of nominal values.

Plasma samples: LC-MS/MS methods for the quantitative determination of the test article in mouse plasma were developed with an internal standard. Benchtop stability of the compound in mouse plasma was determined at mid QC concentrations in triplicate at $0,2 \mathrm{~h}$ at room temperature. The stability was determined using mean peak area ratio of $\mathrm{T} 2 / \mathrm{T} 0$ sample. If the mean peak area ratio is within $80 \% \sim 120 \%$, the test article in the plasma is considered stable for $2 \mathrm{~h}$ at room temperature. A standard curve consists of eight non-zero calibration standards for the LC-MS/MS method with a target lower limit of quantification (LLOQ) at $\leq 3$ $\mathrm{ng} \mathrm{mL} \mathrm{m}^{-1}$. A set of QC samples consists of three concentration levels (low, middle and high). The sample analysis was performed concurrently with a set of calibration standards and two sets of QC samples using the LC-MS/MS method.

Acceptance criteria for plasma bioanalytical run: A minimum of six calibration standards is back calculated to within $\pm 20 \%$ of their nominal concentrations; and a minimum of 4 out of 6 QC samples is back calculated to within $\pm 20 \%$ of their nominal concentrations.

Analyte interference: The mean calculated concentration in the single blank matrix should be $\leq 0.5$ times the LLOQ.

Carryover:. the mean calculated carry-over concentration in the single blank matrix immediately after the highest standard injection should be $\leq$ LLOQ.

Data analysis: Plasma concentration vs. time data from individual animals was analysed by WinNonLin non-compartmental model (Phoenix WinNonlin 6.2.1, Pharsight, Mountain View, CA). Pharmacokinetic parameter $C_{0}, T_{1 / 2}, \mathrm{CL}, \mathrm{Vd}_{\mathrm{ss}}$, $C_{\max }, T_{\max }, \mathrm{AUC}_{0 \text {-last }}, \mathrm{AUC}_{0 \text {-inf }}, \% F, \mathrm{MRT}_{0 \text {-last }}, \mathrm{MRT}_{0 \text {-inf }}$ and graphs of plasma concentration vs. time profile were derived.

MRSA thigh infection in vivo efficacy model. Performed at the University of Queensland, following similar previous literature procedures ${ }^{52}$.

Summary: Adult (8-week-old) female CD1 mice were made neutropenic by two injections of cyclophosphamide 4 days and 1 day prior to infection. An inoculum of $10^{5}$ CFU MRSA (Strain ATCC $43300^{\mathrm{Tm}}$ ) was injected intramuscularly into both left and right thighs of all mice. Two hours after initiation of infection, saline,

vancomycin or vancapticin compounds were injected subcutaneously in the lower back region. After an additional $2 \mathrm{~h}$, a $50 \mu \mathrm{L}$ sample of blood was obtained from the tail bleed to analyse for presence of antibiotic compound. At $24 \mathrm{~h}$ following infection, mice were killed and an additional blood sample collected for compound analysis. Thighs were then removed, weighed and homogenised in a fixed volume of saline. The homogenate solution was filtered, diluted and seeded onto agar plates, which wre incubated overnight at $37^{\circ} \mathrm{C}$. Colony counts were used to establish the CFU in the thigh homogenates, the CFU thigh ${ }^{-1}$ and the $\mathrm{CFU} \mathrm{g}^{-1}$ of thigh.

Protocol: Compound preparation: Cyclophosphamide monohydrate (Sigma) was dissolved in sterile saline to a concentration of $30 \mathrm{mg} \mathrm{mL}^{-1}$. Likewise, vancomycin (Sigma) and vancapticins were also dissolved in sterile saline to a final concentration of $60 \mathrm{mg} \mathrm{mL}^{-1}$ and $18.5 \mathrm{mg} \mathrm{mL}^{-1}$ respectively. All compounds were prepared in low binding Eppendorf tubes and kept at $-20^{\circ} \mathrm{C}$ until used. 
Preparation of injectable MRSA solution: An MRSA subculture bacterial isolate (ATCC $43300^{\mathrm{mt}}$ ) was taken from the storage at $-80^{\circ} \mathrm{C}$ and freshly seeded on agar plates for overnight growth. From the overnight culture preparation, a single colony was diluted into $10-12 \mathrm{~mL}$ of $\mathrm{MHB}$ and incubated overnight at $37^{\circ} \mathrm{C}$. A logphase subculture was obtained by adding $100 \mu \mathrm{L}$ of overnight subculture in $10 \mathrm{~mL}$ MHB and incubated for a further $2-3 \mathrm{~h}$. Finally, the $\mathrm{OD}_{600}$ value of the bacterial suspension was determined and the colony forming units per millilitre (CFU mL ${ }^{-1}$ ) extrapolated. A full dilution of the bacterial cell suspension in saline was achieved by washing $(3220 \times g$ for $10 \mathrm{~min})$ and the $\mathrm{OD}_{600}$ in saline determined. The suspension was then diluted out accordingly in order to achieve a $2 \times 10^{6} \mathrm{CFU} \mathrm{mL}^{-1}$ solution $\left(10^{5} \mathrm{CFU}\right.$ in $\left.50 \mu \mathrm{L}_{\text {thigh }}{ }^{-1}\right)$.

Quantification of injected MRSA solution: In order to be able to correlate the actual $\mathrm{CFU} \mathrm{mL} \mathrm{m}^{-1}$ present in the MSRA injection solution with the estimated CFU $\mathrm{mL}^{-1}$ based on the $\mathrm{OD}_{600}$ readings, a standard plate count from the MSRA injection solution was performed. Thus, $10 \mu \mathrm{L}$ of the injectable MRSA suspension was diluted down to 10-1000 fold, each dilution plated out onto agar and incubated at $37^{\circ} \mathrm{C}$ for $24 \mathrm{~h}$. From the estimated $2 \times 10^{6} \mathrm{CFU} \mathrm{mL} \mathrm{m}^{-1}$ solution, $18 \mathrm{CFU}$ per $10 \mu \mathrm{L}$ were found in the 1:1000 dilution, giving a final concentration of $1.8 \times 10^{6}$ $\mathrm{CFU} \mathrm{mL} \mathrm{m}^{-1}$ for the actual injectable MRSA solution.

In vivo experimental assay: Eight-week-old female outbred CD1 mice (UQBRAIBN) were rendered neutropenic by injecting two doses of cyclophosphamide intraperitoneally 4 days $\left(150 \mathrm{mg} \mathrm{kg}^{-1}\right)$ and 1 day $\left(100 \mathrm{mg} \mathrm{kg}^{-1}\right)$ prior to experimental infection. The infection model using MRSA was established by intramuscular injection of $50 \mu \mathrm{L}$ of early-log-phase bacterial MRSA suspension (around $2 \times 10^{6}$ $\mathrm{CFU} \mathrm{mL}{ }^{-1}$ ) in saline into both thigh muscles. After $2 \mathrm{~h}$, a single dose of vancomycin $\left(200 \mathrm{mg} \mathrm{kg}^{-1}\right)$ or compound of this invention $\left(25 \mathrm{mg} \mathrm{kg}^{-1}\right)$ was administered by a subcutaneous injection over the interscapular (area at back of the neck). Untreated animals received equivalent volume of saline (Baxter). The mice were monitored for signs of normal behaviour (i.e. grooming, eating, drinking, sleeping and alertness) during and following dosing. Two $\mathrm{h}$ after saline/antibiotic treatment, $0.05 \mathrm{~mL}$ of blood was collected by tail incision. $24 \mathrm{~h}$ after MRSA infection, mice were killed and blood collected from the heart by cardiac puncture (saline group) or by tail incision (vancomycin and vancapticin treated groups). For each mouse, both thighs were collected aseptically by cutting the leg at the hip and knee, placed in $10 \mathrm{~mL}$ of cold sterile saline and the individual weight of each thigh recorded.

Plasma sample preparation: Blood samples were taken at $2 \mathrm{~h}$ (tail incision) and $22 \mathrm{~h}$ (cardiac puncture or tail incision) post saline/vancomycin/vancapticin treatment using Lithium-Heparin Microvette ${ }^{\circledR}$ (Sardest) or using heparin coated syringes. All samples were kept at $4^{\circ} \mathrm{C}$ and spun down at $10,000 \times g$ for $15 \mathrm{~min}$. Plasma was collected and kept at $-80^{\circ} \mathrm{C}$ until used.

Thigh homogenates and CFU determination: Thighs were homogenised at 20,000 rpm for $15 \mathrm{~s}$ using a Polytron MR2500E using a $200 \mathrm{~mm}$ probe (Kinematica). Homogenate solutions were filtered using a $100 \mu \mathrm{m}$ pore size filter (BD) and $1 \mathrm{~mL}$ of filtrate solution placed on ice and serial dilutions promptly done (1:10 and 1:100) and seeded onto appropriate nutrient agar plates (Bactolaboratories) and incubated at $37^{\circ} \mathrm{C}$ overnight. Colonies were counted the next day and CFU thigh ${ }^{-1}$ and the CFU g ${ }^{-1}$ of thigh calculated based on the plate count and dilution factor.

\section{S. pneumoniae lung infection in vivo efficacy model. Performed by Eurofins,} Taiwan, following similar previous literature procedures ${ }^{29,53}$.

Summary: The study objective was to evaluate the antimicrobial activity of test articles in a lung infection model with S. pneumoniae (ATCC $6301^{\mathrm{m}}$ ). Male ICR mice were inoculated intratracheally (IT) with $S$. pneumoniae at an inoculum size of $2.96 \times 10^{6} \mathrm{CFU}$ per mouse ( $20 \mu \mathrm{L}$ per mouse). Vancapticins 19 and 24 were administered at $25 \mathrm{mg} \mathrm{kg}^{-1}$ to separate groups of mice by subcutaneous (SC) injection $2 \mathrm{~h}$ post-infection. The reference standard, vancomycin $\mathbf{1}$, was dosed at $25 \mathrm{mg} \mathrm{kg}^{-1} \mathrm{qd} \mathrm{SC}$ at $2 \mathrm{~h}$ after IT inoculation. Mortality was observed for 10 days. An increase in survival rate of 50 percent or more $(\geq 50 \%)$ of the treated animals relative to the vehicle group indicates significant antimicrobial activity. Subcutaneous injection (SC) of 19 and 24 at $25 \mathrm{mg} \mathrm{kg}^{-1}$ was associated with pronounced increase in the 10-day survival rate relative to the vehicle group, indicating significant antimicrobial activity. The vancomycin treated group, $25 \mathrm{mg}$ $\mathrm{kg}^{-1}$ SC qd, also exhibited significant antimicrobial activity ( $\geq 50 \%$ survival rate) relative to the vehicle control.

Protocol: Test substances at $25 \mathrm{mg} \mathrm{kg}^{-1}$ were each administered subcutaneously (SC) to test animals $2 \mathrm{~h}$ after inoculation. The dosing volume was $10 \mathrm{~mL} \mathrm{~kg}^{-1}$.

Animals:. Male ICR mice weighing $22 \pm 2 \mathrm{~g}$ were provided by BioLasco Taiwan (under a Charles River Laboratories Technology Licensee). Space allocation for 5 animals was $29 \times 18 \times 13 \mathrm{~cm}$. Mice were housed in animal cages and were maintained in a controlled temperature $\left(20-23^{\circ} \mathrm{C}\right)$ and humidity $(50-80 \%)$ environment with $12 \mathrm{~h}$ light/dark cycles for at least three days at Eurofins Panlabs Taiwan, Ltd. laboratory prior to use. Free access to standard lab chow for mice (Laboratory Rodent Diet MFG (Oriental Yeast Co., Ltd. Japan)) and tap water in bottle were granted. All aspects of this work including housing, experimentation and disposal of animals were performed in general accordance with the Guide for the Care and Use of Laboratory Animals (National Academy Press, Washington, DC, 2011)

Organism: S. pneumoniae (ATCC $\left.6301^{\mathrm{m}}\right)$ was obtained from the American Type Culture Collection (Rockville, MD, USA). The bacterial culture was diluted in brain-heart infusion broth containing to achieve the target inoculum size of 1.0-5.0 $\times$ $10^{6} \mathrm{CFU}$ per $20 \mu \mathrm{L}$ that would be inoculated intratracheally into each animal.

Chemicals: Bacto agar (Cat\# 214040, BD DIFCO, USA), brain heart infusion broth (Cat\# 237500, BD, USA), fetal bovine serum (Cat\# 30071.03, HyClone, USA), sodium chloride (Cat\# S7653, SIGMA-Aldrich, USA), vancomycin (Cat\# V2002, Sigma, USA) and water for injection (WFI) (Tai-Yu, Taiwan).

Equipment: Animal cage (Allentown, USA), biokinetic reader (Bio-Tek, USA), biological safety cabinet (NuAire, USA), centrifuge (Eppendrof 5810 R, Germany), laminar flow (Chao-Shin, Taiwan), orbital shaking incubator (Firstek Scientific, Taiwan), Pipetman P100 (Gilson, France), refrigerated incubator (Hotpack, USA) and ultra-low temperature freezer (NuAire, USA).

Methods: Assay \# 608100 S. pneumoniae (ATCC ${ }^{\circ} 6301^{\mathrm{mm}}$ ), Infected Lung Model. Groups of 10 male specific-pathogen-free ICR mice weighing $22 \pm 2 \mathrm{~g}$ were used. Acute pneumonia was induced by intratracheal inoculation with a $\mathrm{LD}_{90-100}$ dose $\left(2.96 \times 10^{6} \mathrm{CFU}\right.$ mouse $\left.^{-1}\right)$ of $S$. pneumoniae (ATCC $6301^{\mathrm{m}}$ ) suspended in $20 \mu \mathrm{L}$ of BHI. Vehicle $\left(10 \mathrm{~mL} \mathrm{~kg}^{-1}\right)$, vancomycin and test substances at $25 \mathrm{mg} \mathrm{kg}^{-1}$ were each administered subcutaneously $2 \mathrm{~h}$ post-infection. Mortality was recorded daily for 10 days following inoculation. Increase of 50 percent or more $(\geq 50 \%)$ in survival rate relative to the vehicle control group indicates significant anti-infective activity.

Bioluminescence IP infection in vivo model. Performed at the University of Queensland, following similar previous literature procedures ${ }^{27}$. Xen-29 (Caliper LifeSciences), a methicillin-sensitive S. aureus (MSSA) strain which contains a copy of the modified luxABCDE operon of Photorhabdus luminescens was taken from the storage at $-80^{\circ} \mathrm{C}$ and freshly seeded on agar plates for overnight growth at $37^{\circ}$ C. From the overnight culture preparation, a single colony (tested for bioluminescence) was diluted into $10 \mathrm{~mL}$ of $\mathrm{MHB}$ and incubated overnight at $37^{\circ} \mathrm{C}$. A mid log-phase subculture was obtained by adding $100 \mu \mathrm{L}$ of overnight subculture in 10 $\mathrm{mL} \mathrm{MHB}$ and incubated for a further $2-3 \mathrm{~h}$. Finally, the $\mathrm{OD}_{600}$ value of the bacterial suspension was determined and the colony forming units per millilitre (CFU $\mathrm{mL}^{-1}$ ) was extrapolated. The suspension was then diluted out accordingly in order to achieve a $2.5 \times 10^{8} \mathrm{CFU} \mathrm{mL} \mathrm{m}^{-1}$ solution $\left(2.5 \times 10^{7} \mathrm{CFU}\right.$ in $\left.100 \mu \mathrm{L}\right)$. Seven-weekold female outbred CD1 mice (UQBR-UQCCR) were rendered neutropenic by injecting two doses of cyclophosphamide (Sigma-Aldrich) intraperitoneally 4 days $\left(150 \mathrm{mg} \mathrm{kg}^{-1}\right)$ and 1 day $\left(100 \mathrm{mg} \mathrm{kg}^{-1}\right)$ prior to experimental infection. The peritonitis infection model using bioluminescent Xen-29 was established by intraperitoneal injection of $100 \mu \mathrm{L}$ of the adjusted bacterial Xen-29 suspension (around $2.5 \times 10^{7} \mathrm{CFU}$ ) in saline. $30 \mathrm{~min}$ after bacterial inoculation, a single dose of daptomycin $\left(50 \mathrm{mg} \mathrm{kg}^{-1}\right)$, vancomycin $\left(200 \mathrm{mg} \mathrm{kg}^{-1}\right)$ or vancapticin $\left(25 \mathrm{mg} \mathrm{kg}^{-1}\right)$ was administered by a subcutaneous injection over the interscapular area (area at back of the neck). Untreated animals received equivalent volume of saline (Baxter). Mice were monitored for signs of normal behaviour (i.e. grooming, eating, drinking, sleeping and alertness) during and following dosing. Blood samples $(50 \mu \mathrm{L})$ were taken $5.5 \mathrm{~h}$ post Xen-29 inoculation by tail bleed using Lithium-Heparin Microvettes ${ }^{\circledast}$ (Sardest). All samples were kept at $4{ }^{\circ} \mathrm{C}$ and spun down at $10,000 \times g$ for 15 min. Plasma samples were collected and kept at $-80^{\circ} \mathrm{C}$ until used; while the pellets were re-suspended in $100 \mu \mathrm{L}$ of sterile saline, serial diluted and spread on agar plates for overnight incubation at $37^{\circ} \mathrm{C}$. Xen- 29 colonies were then counted, with the $\mathrm{CFU} \mathrm{mL} \mathrm{m}^{-1}$ blood calculated. After killing, each mouse was opened and intraperitoneal swabs were taken for CFU determination. Individual spleens were also harvested aseptically, homogenised in $100 \mu \mathrm{L}$ of sterile saline by crushing the tissue with a syringe plunger against a $50 \mu \mathrm{m}$ filter, serial diluted and plated on agar plates for $\mathrm{O} / \mathrm{N}$ incubation at $37^{\circ} \mathrm{C}$. Xen-29 colonies from intraperitoneal swabs and spleens were then verified. Luminescent images were acquired using the Xenogen IVIS-200 Optical In Vivo Imaging System (PerkinElmer). Luminescent images were quantified with the IVIS Living Image software where the total flux (number of photons/second) was calculated by a user defined region of interest (ROI) covering the infection sites.

Data availability. All relevant data are available in this article and its Supplementary Information files, or from the corresponding authors on request. 
Received: 24 November 2016 Accepted: 8 November 2017

Published online: 02 January 2018

\section{References}

1. U.S. Department of Health and Human Services. Antibiotic Resistance Threats in the United States (Centres for Disease Control and Prevention, Georgia, 2013).

2. WHO. Antimicrobial Resistance Global Report on Surveillance (WHO, Geneva, 2014).

3. Australian Commission on Safety and Quality in Health Care (ACSQHC). AURA 2016: First Australian Report on Antimicrobial Use and Resistance in Human Health (ACSQHC, Sydney, 2016).

4. Review on Antimicrobial Resistance. Tackling Drug-Resistant Infections Globally: An Overview Of Our Work. (AMR, London, 2016).

5. PEW. A Scientific Roadmap for Antibiotic Discovery. (PEW, Philadelphia, 2016).

6. Howden, B. P., Davies, J. K., Johnson, P. D. R., Stinear, T. P. \& Grayson, M. L. Reduced vancomycin susceptibility in Staphylococcus aureus, including vancomycin-intermediate and heterogeneous vancomycin-intermediate strains: resistance mechanisms, laboratory detection, and clinical implications. Clin. Microbiol. Rev. 23, 99-139 (2010).

7. McGuinness, W. A., Malachowa, N. \& DeLeo, F. R. Vancomycin resistance in Staphylococcus aureus. Yale. J. Biol. Med. 90, 269-281 (2017).

8. Han, J. H., Mascitti, K. B., Edelstein, P. H., Bilker, W. B. \& Lautenbach, E. Effect of reduced vancomycin susceptibility on clinical and economic outcomes in Staphylococcus aureus bacteremia. Antimicrob. Agents Chemother. 56, 5164-5170 (2012).

9. van Hal, S. J., Lodise, T. P. \& Paterson, D. L. The clinical significance of vancomycin minimum inhibitory concentration in Staphylococcus aureus infections: a systematic review and meta-analysis. Clin. Infect. Dis. $\mathbf{5 4}$ 755-771 (2012).

10. Linden, P. K. Treatment options for vancomycin-resistant enterococcal infections. Drugs 62, 425-441 (2002).

11. Hayden, M. K. et al. Development of daptomycin resistance in vivo in methicillin-resistant Staphylococcus aureus. J. Clin. Microbiol. 43, 5285-5287 (2005).

12. Wilson, P. et al. Linezolid resistance in clinical isolates of Staphylococcus aureus. J. Antimicrob. Chemother. 51, 186-188 (2003).

13. Smith, D. A., Di, L. \& Kerns, E. H. The effect of plasma protein binding on in vivo efficacy: misconceptions in drug discovery. Nat. Rev. Drug Discov. 9, 929-939 (2010).

14. Peetla, C., Stine, A. \& Labhasetwar, V. Biophysical interactions with model lipid membranes: applications in drug discovery and drug delivery. Mol. Pharm. 6, 1264-1276 (2009).

15. Wright, L. P. \& Philips, M. R. CAAX modification and membrane targeting of Ras. J. Lipid Res. 47, 883-891 (2006).

16. Murray, D. et al. Electrostatics and the membrane association of Src: theory and experiment. Biochem. 37, 2145-2159 (1998).

17. Leung, K. F., Baron, R. \& Seabra, M. C. Geranylgeranylation of Rab GTPases. J. Lipid Res. 47, 467-475 (2006).

18. Zhou, W. J., Parent, L. J., Wills, J. W. \& Resh, M. D. Identification of a membrane-binding domain within the amino-terminal region of humanimmunodeficiency-virus type-1 Gag protein which interacts with acidic phospholipids. J. Virol. 68, 2556-2569 (1994).

19. Seykora, J. T., Myat, M. M., Allen, L. A. H., Ravetch, J. V. \& Aderem, A Molecular determinants of the myristoyl-electrostatic switch of MARCKS. J. Biol. Chem. 271, 18797-18802 (1996).

20. Mclaughlin, S. \& Aderem, A. The myristoyl-electrostatic switch - a modulator of reversible protein-membrane interactions. Trends Biochem. Sci. 20, 272-276 (1995).

21. Murray, D., Arbuzova, A., Honig, B. \& McLaughlin, S. The role of electrostatic and nonpolar interactions in the association of peripheral proteins with membranes. Curr. Top. Membr. 52, 277-307 (2002).

22. Beauregard, D. A., Williams, D. H., Gwynn, M. N. \& Knowles, D. J. Dimerization and membrane anchors in extracellular targeting of vancomycin group antibiotics. Antimicrob. Agents Chemother. 39, 781-785 (1995).

23. Mackay, J. P. et al. Glycopeptide antibiotic-activity and the possible role of dimerization - a model for biological signaling. J. Am. Chem. Soc. 116, $4581-4590$ (1994).

24. Malabarba, A., Nicas, T. I. \& Thompson, R. C. Structural modifications of glycopeptide antibiotics. Med. Res. Rev. 17, 69-137 (1997).

25. Sigal, C. T., Zhou, W., Buser, C. A., McLaughlin, S. \& Resh, M. D. Aminoterminal basic residues of Src mediate membrane binding through electrostatic interaction with acidic phospholipids. Proc. Natl. Acad. Sci. USA 91, 12253-12257 (1994).
26. Buser, C. A., Sigal, C. T., Resh, M. D. \& McLaughlin, S. Membrane binding of myristylated peptides corresponding to the $\mathrm{NH} 2$ terminus of Src. Biochem. 33, 13093-13101 (1994).

27. Mortin, L. I. et al. Rapid bactericidal activity of daptomycin against methicillinresistant and methicillin-susceptible Staphylococcus aureus peritonitis in mice as measured with bioluminescent bacteria. Antimicrob. Agents Chemother. 51 1787-1794 (2007).

28. Louie, A. et al. Pharmacodynamics of daptomycin in a murine thigh model of Staphylococcus aureus infection. Antimicrob. Agents Chemother. 45, 845-851 (2001).

29. Reyes, N. et al. Efficacy of telavancin (TD-6424), a rapidly bactericidal lipoglycopeptide with multiple mechanisms of action, in a murine model of pneumonia induced by methicillin-resistant Staphylococcus aureus. Antimicrob. Agents Chemother. 49, 4344-4346 (2005).

30. Nielsen, E. I., Cars, O. \& Friberg, L. E. Pharmacokinetic/pharmacodynamic (PK/PD) indices of antibiotics predicted by a semimechanistic PKPD model: a step toward model-based dose optimization. Antimicrob. Agents Chemother. 55, 4619-4630 (2011).

31. Silverman, J. A., Mortin, L. I., Vanpraagh, A. D., Li, T. \& Alder, J. Inhibition of daptomycin by pulmonary surfactant: in vitro modeling and clinical impact. $J$. Infect. Dis. 191, 2149-2152 (2005).

32. Reynolds, P. E. Structure, biochemistry and mechanism of action of glycopeptide antibiotics. Eur. J. Clin. Microbiol. Infect. Dis. 8, 943-950 (1989).

33. Ge, M. et al. Vancomycin derivatives that inhibit peptidoglycan biosynthesis without binding D-Ala D-Ala. Science 284, 507-511 (1999).

34. Cooper, M. A. \& Williams, D. H. Binding of glycopeptide antibiotics to a model of a vancomycin-resistant bacterium. Chem. Biol. 6, 891-899 (1999).

35. Wade, D. et al. All D-amino acid-containing channel-forming antibiotic peptides. Proc. Natl. Acad. Sci. USA 87, 4761-4765 (1990).

36. Sims, P. J., Waggoner, A. S., Wang, C. H. \& Hoffman, J. F. Studies on the mechanism by which cyanine dyes measure membrane potential in red blood cells and phosphatidylcholine vesicles. Biochemistry 13, 3315-3330 (1974)

37. Belley, A. et al. Oritavancin kills stationary-phase and biofilm Staphylococcus aureus cells in vitro. Antimicrob. Agents Chemother. 53, 918-925 (2009).

38. Belley, A. et al. Oritavancin disrupts membrane integrity of Staphylococcus aureus and vancomycin-resistant enterococci to effect rapid bacterial killing. Antimicrob. Agents Chemother. 54, 5369-5371 (2010).

39. Arndt-Jovin, D. J. \& Jovin, T. M. Fluorescence labeling and microscopy of DNA. Methods Cell. Biol. 30, 417-448 (1989).

40. Muller, A. et al. Daptomycin inhibits cell envelope synthesis by interfering with fluid membrane microdomains. Proc. Natl. Acad. Sci. USA 113, E7077-E7086 (2016).

41. Mani, N. et al. In vitro characterization of the antibacterial spectrum of novel bacterial type II topoisomerase inhibitors of the aminobenzimidazole class. Antimicrob. Agents Chemother. 50, 1228-1237 (2006).

42. Young, K. In vitro antibacterial resistance selection and quantitation. Curr. Protocol. Pharmacol. https://doi.org/10.1002/0471141755.ph13a06s34 (2006).

43. Friedman, L., Alder, J. D. \& Silverman, J. A. Genetic changes that correlate with reduced susceptibility to daptomycin in Staphylococcus aureus. Antimicrob. Agents Chemother. 50, 2137-2145 (2006).

44. Dufour, S. et al. Hemolytic activity of new linear surfactin analogs in relation to their physico-chemical properties. Biochim. Biophys. Acta 1726, 87-95 (2005).

45. Pandey, B. K. et al. Cell-selective lysis by novel analogues of melittin against human red blood cells and Escherichia coli. Biochem. 49, 7920-7929 (2010).

46. Chattopadhyay, A. \& London, E. Fluorimetric determination of critical micelle concentration avoiding interference from detergent charge. Anal. Biochem. 139, 408-412 (1984)

47. Reynolds, P. E. Peptidoglycan synthesis in bacilli. I. Effect of temperature on the in vitro system from Bacillus megaterium and Bacillus stearothermophilus. Biochim. Biophys. Acta 237, 239-254 (1971).

48. Di, L., Kerns, E. H., Hong, Y. \& Chen, H. Development and application of high throughput plasma stability assay for drug discovery. Int. J. Pharm. 297, 110-119 (2005).

49. Stringer, R., Nicklin, P. L. \& Houston, J. B. Reliability of human cryopreserved hepatocytes and liver microsomes as in vitro systems to predict metabolic clearance. Xenobiotica 38, 1313-1329 (2008).

50. Barter, Z. E. et al. Scaling factors for the extrapolation of in vivo metabolic drug clearance from in vitro data: reaching a consensus on values of human microsomal protein and hepatocellularity per gram of liver. Curr. Drug Metab. 8, 33-45 (2007).

51. Davies, B. \& Morris, T. Physiological parameters in laboratory animals and humans. Pharm. Res. 10, 1093-1095 (1993).

52. Andes, D. \& Craig, W. A. In vivo activities of amoxicillin and amoxicillinclavulanate against Streptococcus pneumoniae: application to breakpoint determinations. Antimicrob. Agents Chemother. 42, 2375-2379 (1998).

53. Azoulay-Dupuis, E. et al. Efficacy of BAL5788, a prodrug of cephalosporin BAL9141, in a mouse model of acute pneumococcal pneumonia. Antimicrob. Agents Chemother. 48, 1105-1111 (2004). 


\section{Acknowledgements}

We thank Caliper Biosciences (Perkin Elmer) for supply of the bioluminescent MSSA bacteria Xen-29. M.A.C. is a current National Health and Medical Research Council (NHMRC) Principal Research Fellow (APP1059354) and former Australia Fellow (AF511105). J.A.R. is a NHMRC Career Development Fellow (APP1048652). This work was supported by a Wellcome Trust Seeding Drug Discovery Award 094977/Z/10/Z, and NHMRC Project Grants APP631632 and APP1026922. R.A.G.S acknowledges the support of the UK Medical Research Council and the UK NIHR Biomedical Research Council at Guy's Hospital, London. The following strains were provided by the Network on Antimicrobial Resistance in S. aureus (NARSA) for distribution by BEI Resources, NIAID, NIH: S. aureus NRS-1, and VRS-4. Strains S. aureus ATCC 4300, ATCC 29213, S. pneumoniae ATCC 700677 and E. faecium ATCC 51559, B. megaterium KM (ATCC 13632), B. subtilis NRS-231 (ATCC 6633) and human cell lines HepG2 (ATCC HB-8065) and HEK293 (ATCC CRL-1573), were acquired from American Type Culture Collection (ATCC).

\section{Author contributions}

M.A.C. designed the project with input from J.R.B., A.P.G.B., R.A.G.S. (design of the electrostatic effector sequence), and M.A.T.B., J.A.R. and D.L.P. The manuscript was written by M.A.T.B., M.A.C. and K.A.H. with input from all authors. M.A.T.B., M.A.C. and M.S.B. designed and coordinated experiments and analysed results. Y.G., J.R.B., C.M., R.P., T.A.B., T.K., K.A.H., Z.Z., F.L. J.C.L. and J.Z. designed, synthesised, purified and analysed compounds. M.S.B., R.P. and D.J.E. purified and analysed compounds. Y.G., So.R., A.M.K., M.A., A.G.E., W.P., M.C., J.X.H., Z.Z., J.E.D., N.H.D., Se.R., A.B.S. and H.E.S. carried out in vitro and in vivo biological assays. All authors discussed the results and commented on the manuscript.

\section{Additional information}

Supplementary Information accompanies this paper at https://doi.org/10.1038/s41467017-02123-w.
Competing interests: M.A.C. and M.A.T.B are listed as inventors in patent application WO 2015/117196-A1 'Antibacterial Agents', which includes compounds described in this article. The remaining authors declare no competing financial interests.

Reprints and permission information is available online at http://npg.nature.com/ reprintsandpermissions/

Publisher's note: Springer Nature remains neutral with regard to jurisdictional claims in published maps and institutional affiliations.

\section{(c) (1)}

Open Access This article is licensed under a Creative Commons Attribution 4.0 International License, which permits use, sharing, adaptation, distribution and reproduction in any medium or format, as long as you give appropriate credit to the original author(s) and the source, provide a link to the Creative Commons license, and indicate if changes were made. The images or other third party material in this article are included in the article's Creative Commons license, unless indicated otherwise in a credit line to the material. If material is not included in the article's Creative Commons license and your intended use is not permitted by statutory regulation or exceeds the permitted use, you will need to obtain permission directly from the copyright holder. To view a copy of this license, visit http://creativecommons.org/ licenses/by/4.0/

(C) The Author(s) 2017 